\title{
Colours and Numerals in \\ Spanish Sign Language (LSE)
}

\author{
Inmaculada C. Báez-Montero ${ }^{1}$ \\ Ana María Fernández-Soneira
}

\section{Introduction ${ }^{2}$}

...although slowing down or reversals of changes are possible /.../, change usually creeps on inexorably, hindered to some extent by literacy and the other social factors, but not for long.

(Aitchison 2001:149)

This chapter presents an account of variation in Spanish Sign Language (Lengua de Signos Española, LSE), through a study of signs for colours and numerals. In the section on colour signs we focus on the description of variants in the form of the signs as well as in the meanings. For the former, a diachronic perspective is adopted, and, with the help of dictionaries and glossaries, we analyse variations in the articulation of existing signs for expressing colours. For the latter (variation in meaning), we analyse similarities and differences between LSE and spoken Spanish in the expression of colour-based idioms. For this part of our analysis we have relied on several deaf consultants. ${ }^{3}$

In the section for the study of numerals, we focus mainly on the expression of cardinal numbers, on the most frequent expressions, and on alternative systems of expression in specific geographical areas. We also deal with ordinals and fractions, and with numeral incorporation, a typical phenomenon in sign languages (cf. Valli and Lucas 2000).

First, however, a wider account of variation in LSE provides a background for the specific focus on numerals and colours. A description of the method employed is also given prior to delving into what was found regarding the range of forms within these two fascinating domains.

As all languages are dynamic systems they adapt to the expressive necessities of their speakers, and present variations, in time and space, which are sometimes consolidated into linguistic change. Variation thrives within the 
language system properties, i.e. in the dynamic character of every language system. Variation is therefore an inherent property of languages and it results from the manifestation of language creativity and individual innovation. Against the natural linguistic variations in LSE which are derived from timerelated change, geographical dispersion, social, situational and generational differences, and the lack of a standarised written language system, there are measures being carried out by some associations and federations for the deaf that counterbalance the diverging factors in the language of the deaf community, by trying to favour standardisation procedures.

Currently, neither research on corpus linguistics nor sociolinguistic studies have provided descriptions of those variations that would help delimit variation among the three visual-gestural languages that are today officially recognised on the Iberian Peninsula: the Spanish Sign Language, the Catalan Sign Language and the Portuguese Sign Language (official since 1997), or among the isoglosses of any of these three languages. As Amaral et al. 1994: 39 observe:

There exists, in fact, a community of the deaf in Portugal that has, as its mother tongue, the Lingua Gestual Portuguesa (Portuguese Sign Language) ... There exist, just as in Portuguese, regional variants in Lisbon and Oporto, as well as other sociolinguistic variants, depending on the degree of literacy and on the profession of the deaf in these communities. [ $\left.\mathrm{S}^{4}\right]$

In her work on LSE, M. a Ángeles Rodríguez (1992) writes about variation in Spain that "[ $\mathrm{t}]$ he differences are more distinct between cities that are geographically more distant ... In Madrid and Valladolid, which are not too distant, signing is done in the same way, while it is performed differently in Barcelona". And she explains this assertion in the following way: "Such variants affect only the signed lexicon, but not the communicative-interactional context of the language" [S]. She therefore considers that the differences do not affect comprehension and that it is the geographical distance that correlates with this variation.

The publication Apuntes de lingüistica de la lengua de signos española includes a chapter on variation in LSE by Stephen and Dianne Parkhurst. This work is divided into two main parts: the first one deals with several common methods to examine variants in sign language; the second one gives examples of types of variants as they were observed in México and in Spain. The authors' observations and impressions are expressed as follows:

When we travelled throughout Spain and asked the deaf for their impressions with regard to their own language, we heard comments such as: "We here in Granada sign in a different manner from those in Málaga or Córdoba". When 
they referred to the manner in which "we sign in Granada", they were aware of the fact that sign language in Granada, up to a certain point, was unified. There exists a feeling of identity: "we". At the same time their sign language is different from the language in other cities.

(Parkhurst \& Parkhurst 2000: 222 [S])

The authors, based on factors such as geographical location, school attendance, religious faith and social class, and the signer's gender and age, detect levels of identity and differentiation in dialect (dialect groups) which allow diversity to be reflected. However, they also conclude that even though the results are not sufficient - the study focuses only on the lexicon ${ }^{5}$ - the signers interviewed show, to varying degrees, quite an adequate ability to understand each other without difficulties.

Also worth mentioning are the Diccionario de neologismos de la LSE (1999) where the geographical variants of many of the signs are listed, the Diccionario normativo de la LSE (2008), where is trying to establish a standard, using the regional dialect that imposes itself as a norm, and the studies on variation by Carmen Chapa $(2000 ; 2001)$.

In her research on LSE variation, Carmen Chapa (2000) mentions geographical, social and contextual variation. As for regional variation in LSE, it is apparent mainly in the lexicon, and often has to do with the characteristics of the surroundings. A clear example is found in the signs for the months of the year. In Galicia (NW Spain), the sign used for JUNE makes reference to cherries (it is the time of the year when this fruit is harvested), while in other parts of Spain at least two more variants are acknowledged. Chapa (2000: 301) also refers to the geographical variants for MARCH in Valencia and Madrid.

As for social variation, one of the main factors to be taken into account is school attendance.

Non-geographical origins of LSE variants can easily be related to the development of this language at school ... The influence of two main centres for schools, Madrid and Barcelona, which have attracted children from other neighbouring areas, must have had consequences for language variation.

(Gras Ferrer 2006: 48 [S])

Currently, there are no special schools for the deaf in Spain, due to the fact that deaf children have been integrated into mainstream schools. However, among the adult deaf, we do find people who attended special schools, and the differential signs they use show, above all, lexical variation. In the case of numerals, which are analysed in this article, we shall see that some variants 
of expression are connected with these Schools for the Deaf. As Morales López (2008) asserts, the Schools for the Deaf were the places where the majority of the deaf learned sign language. The schools were continued in Associations for the Deaf, which served as a vehicle of furthering the social integration initiated in the schools. Currently, young deaf people have a higher level of literacy, as they attend mainstream schools, are bilingual in many cases and participate less in the associations. A study that remains to be carried out is how the effects of these factors influence variation in LSE. Also to be analysed is the occurrence of LSE standardisation within regional variants due to its inclusion in the educational environment, the media, interpreting and, more recently, science (see Gras Ferrer 2006 for some explanations of these issues).

As for the awareness of sign language users, Gras Ferrer (2006: 48), in a study on the deaf community in Spain, asserts that some of her consultants when talking about dialectal variants in LSE - said that there are differences not only between different schools but also between autonomous regions.

In some cases, variants motivated by the gender of the signers have been found, and also variants depending on the communicative situation in which the signers are immersed. Chapa (2000: 308) says that "informal registers present a less precise articulation of the signs, the omission of the nondominant hand in some signs, reduced movement, less presence of spoken components and, on the syntactic level, a greater use of simultaneity" [S]. Further, in her 2001 study on situational variation in LSE, she concludes that the spoken component (a.k.a. mouthing or mouth patterns, cf. Boyes Braem $\&$ Sutton-Spence 2001) is more relevant in formal registers than in informal ones (Chapa 2001: 173-174).

Some factors related to social and contextual variation are found in the expression of numerals and quantifiers. For example, the numeral system for multiples of ten used in Galicia shows some variants depending on whether the signer is a man or a woman. Also, the handshape of some signs varies, depending on the physical distance between the interlocutors (i.e. the environment in which the conversation is carried out).

In Spain, the Associations for the Deaf used to play an important role as a factor in linguistic cohesion, as their social dynamics involved carrying out frequent cultural and sports exchanges. However, they are now facing, and even resisting, the arrival of new technologies that facilitate remote, visual exchanges of information. As the associations are not necessary as physical meeting points any more, they are losing the capacity for cohesion they have always had. Part of this role has now shifted to the recently created Confederación Estatal de Personas Sordas (Spanish National 
Confederation of Deaf People, CNSE) and the Centro de Normalización de la Lengua de Signos Española (Spanish Sign Language Standardisation Center, CNLSE).

\section{Methodology}

For this research we have relied on consultants, and also on descriptive, lexiographical and didactic studies in LSE. The majority of our consultants are deaf, but we have also relied on LSE interpreters. Nine consultants have participated, five of whom are deaf (two of them with deaf parents). The four hearing consultants are LSE interpreters. Three consultants are male and six are female, and they are aged 20 to 40 and come from different autonomous regions (Galicia, the Canary Islands, Murcia, and Madrid). A full list of our consultants, with precise indication of their participation, is shown in the table below.

Table 1. Consultants in the two parts of the study

\begin{tabular}{lcc}
\hline Consultants & Colours & Numerals \\
\hline Estefanía (deaf-deaf parents) & $\mathrm{X}$ & \\
Manuel (deaf-deaf parents) & $\mathrm{X}$ & $\mathrm{X}$ \\
Claudia (deaf) & $\mathrm{X}$ & $\mathrm{X}$ \\
Juan Ramón (deaf) & & $\mathrm{X}$ \\
Mónica (deaf) & $\mathrm{X}$ & $\mathrm{X}$ \\
Alba (interpreter) & $\mathrm{X}$ & $\mathrm{X}$ \\
Ruth (interpreter) & $\mathrm{X}$ & $\mathrm{X}$ \\
María (interpreter) & $\mathrm{X}$ & $\mathrm{X}$ \\
Rayco (interpreter) & $\mathrm{X}$ & $\mathrm{X}$ \\
\hline
\end{tabular}

Where we rely on primary data, these have been elicited from consultants on the basis of typological questionnaires covering the semantic domains of colour terms and quantification (see Sagara \& Zeshan, this volume).

This chapter presents a description of colour signs and numeral/quantifier signs in LSE. The structure of these two sections is not identical. Regarding colours, we start with an analysis of the inventory of signs present in LSE for the expression of colours, and their regional and stylistic variants (Sections 3.1 and 3.2). Section 3.3 undertakes a comparative analysis 
between Spanish and LSE with regard to idioms that include reference to colours.

In the case of numeral expressions in LSE, this article focuses mainly on the expression of cardinal numerals, due to their variation, and due to the existence in LSE of variants for the expression of certain units and for multiples of ten up to 90 . We also focus on usage of ordinals, fractions and numeral incorporation, following the order of the items in the abovementioned questionnaires.

\section{Colours}

When an object is present, it should be indicated, rather than described. When it is absent, or needs the presence of an element, it will be sufficient to indicate a similar object that has the required quality. This procedure is followed, for example, for colours, food and temperature, among others.

(Marroquín 1975: 9 [S])

In this section we approach variants along the temporal axis, describing them in terms of diachronic variation. In sociolinguistics, one of the most interesting variables is "age", as it allows the researcher to observe linguistic change across several generations. As López Morales (2004:134) points out, "if a linguistic trait appears among young people but not in older generations, it is probable that it is a recent phenomenon; if it appears only in adult generations, it is most probably a phenomenon falling into disuse" [S].

As we have not been able to draw on a number of consultants of different ages, who might have been able to produce a sufficient number of samples in order to allow us to make more overreaching conclusions, we have opted for a review of publications that give information about diachronic variation, or about change in the colour vocabulary in LSE, i.e. dictionaries, glossaries and publications, such as Fernández Villabrille (1851), Marroquín (1975 and 1981) and DILSE (2008), constituting a selection of publications from the $19^{\text {th }}$ century to the present.

The following results have been extracted from a small field study, and will therefore have to be viewed with caution. As shown in the table above (Table 1), the group of consultants selected for this study is made up of 4 deaf people (two of whom have deaf parents), and 4 interpreters. As for the gender, 6 are female and 2 are male, aged from 20 to 40. The control group is made up of users of sign language who are more than 40 years of age. The latter group was questioned about the results obtained in our research 
among the younger signers. Furthermore, traditional lexicographical sources such as the abovementioned works by Villabrille, Marroquín, etc. have been consulted.

\subsection{Articulation and variation of signs for colours}

In order to describe and contrast the expressions of colour in LSE, our fundamental sources have been the lexicographical studies carried out by CNLSE, backed up by the federations and associations for deaf people in the autonomous regions in Spain (CNSE). These associations rely on the assistance of the Real Academia de la lengua española (RAE) and its Diccionario normativo de la lengua de signos española (DILSE_III) ${ }^{6}$ updated in 2011. Previous studies have also been taken into account, such as the subsequent revisions of Pinedo Peydró (2005) in Diccionario de la lengua de signos española and Cecilia Tejedor (2006) in the Vocabulario Básico, entitled Mil palabras con las manos (A thousand words with the hands).

Table 1 summarises which colour terms are represented in which of the available lexicographic sources.

Table 2. Colour terms included in LSE sources

\begin{tabular}{|c|c|c|c|c|c|c|c|c|c|c|c|}
\hline & white & black & red & green & blue & Yellow & orange & brown & pink & purple & grey \\
\hline $\begin{array}{l}\text { Fernández } \\
\text { Villabrille } \\
(1851)\end{array}$ & & $X$ & $X$ & & & & & & & & $X$ \\
\hline $\begin{array}{l}\text { Marroquín } \\
\text { (1975) }\end{array}$ & $X$ & $X$ & $X$ & $X$ & $X$ & $X$ & & & & & $X$ \\
\hline $\begin{array}{l}\text { Pinedo } \\
\text { Peydró } \\
(2005)\end{array}$ & $X$ & $X$ & $X$ & $X$ & $X$ & $X$ & & & $X$ & & $X$ \\
\hline $\begin{array}{l}\text { Cecilia } \\
\text { Tejedor } \\
(2006)\end{array}$ & $X$ & $X$ & $X$ & $X$ & $X$ & $X$ & $\mathrm{X}$ & $X$ & $X$ & $X$ & $X$ \\
\hline $\begin{array}{l}\text { DILSE } \\
\text { (2011) }\end{array}$ & $X$ & $X$ & $X$ & $X$ & $X$ & $X$ & & & $X$ & & \\
\hline
\end{tabular}

According to Fernández Villabrille (1851:35), the term colores is expressed in the following way: "The colours are, in general, indicated by rubbing the wrist of the left hand with the right hand" [S]. This does not coincide with present-day usage, which is performed by rubbing the lips with the fingertips. 
Under the same heading, he writes: "There are signs for the particular colours". In addition to 'red', 'black' and 'grey', this dictionary includes signs for 'golden', 'light and dark', ${ }^{9}$ and 'shiny'. ${ }^{10}$ Marroquín (1975:53) in his glossary, includes additional terms for 'light (colour)' and 'dark (colour)'. He also points out that for the remaining colours, "some signs are combined with others" and fingerspelling is used.

\section{Yellow}

Figure $1^{11}$ shows the articulation of this colour term as in DILSE and the Vocabulario Básico. The point of contact is the lips. The fingers of the right hand are stretched out and separated, the middle finger slightly flexed close to the lips and moved up and down quickly. As for diachronic variation, it has to be pointed out that this sign is not included in Fernández Villabrille, but it appears in both glossaries by Marroquín (1975:38): "The index and the middle fingers are close to the mouth moving up and down" [S]. In the Diccionario Mímico (Marroquín 1981) there is a photograph showing a sign that is quite different from the one described above. As can be seen in Figure 2, the middle finger is some distance from the mouth.

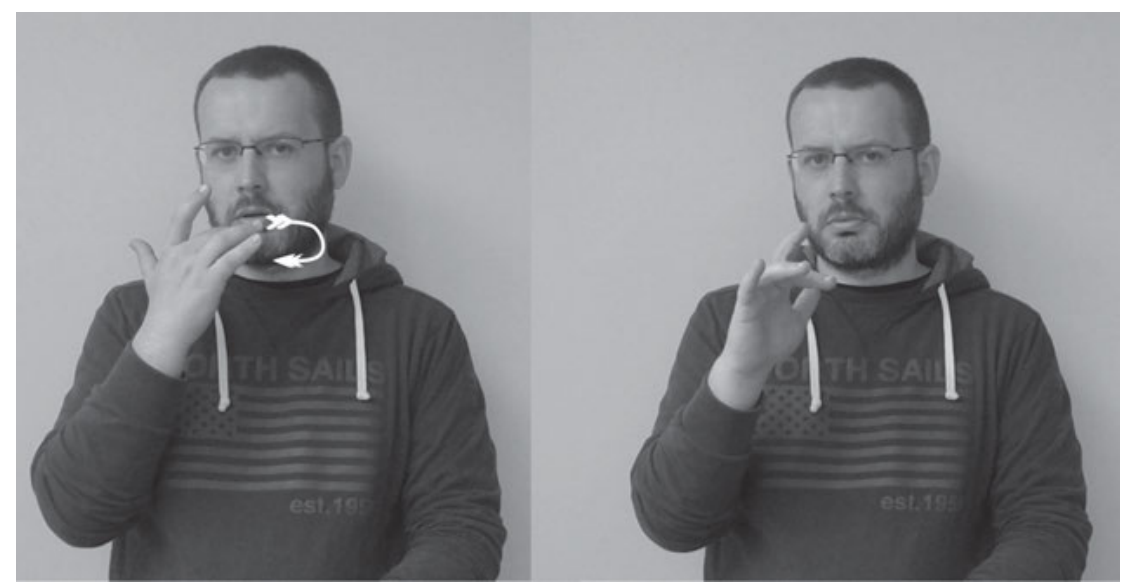

Figure 1.

Figure 2.

All of our consultants signed this colour term in the same way. There is, however, another variant made with the index and middle fingers in front of the mouth, moving up and down (Figures 3-4). Sign language users on 
the Canary Islands have adopted the variant which differs the most, as they draw circles with the index and middle fingers on the cheek (see Figure 5). Another Canary Island variant consists of situating the two fingers on the cheek and making a rotating movement with the forearm.

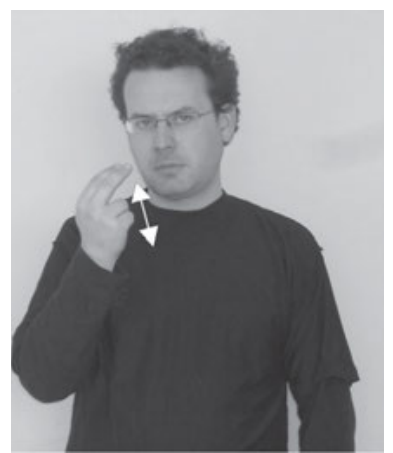

Figure 3.

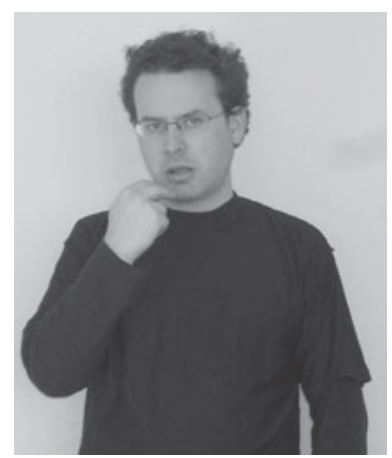

Figure 4.

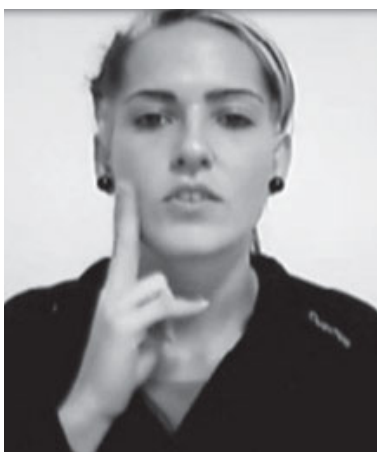

Figure 5.

\section{Blue}

According to the Vocabulario Básico by Cecilia Tejedor (2006), the DILSE (2011) and Pinedo (2005), the sign for the colour blue is made with one swift movement, using the letters a and $\mathrm{z}$ of the manual alphabet (Figure 6). Among our consultants, there is a variant of this sign which consists of the lateral movement of the hand, or moving it to the front (Figure 7). Marroquín (1981) shows another variant which can be seen in Figure 8. The movement is initiated with the extended palm facing the interlocutor and folding the fingers in a rapid movement, leaving only the little finger extended.

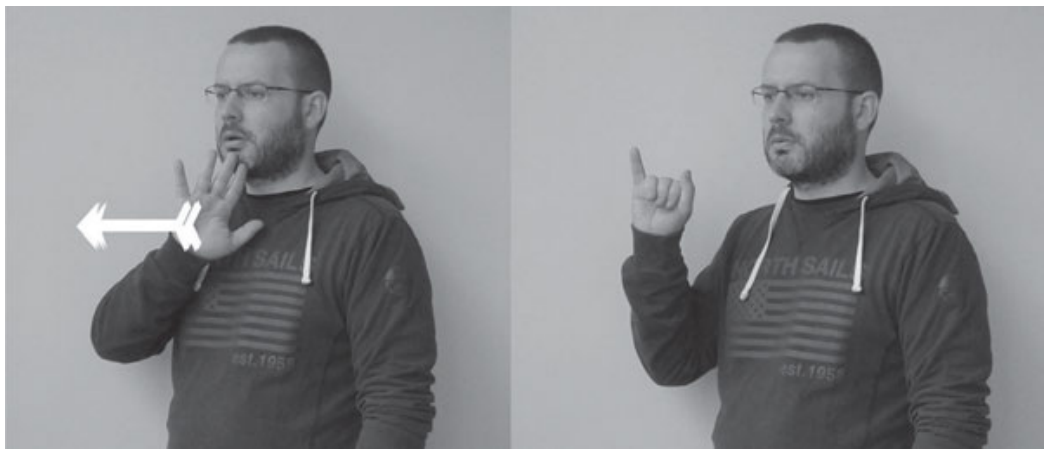

Figure 6. 


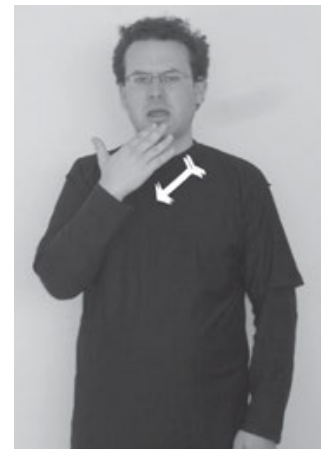

Figure 7.

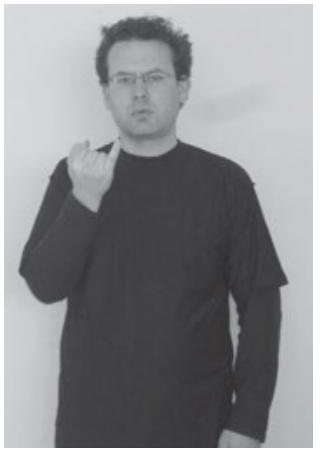

Figure 8.

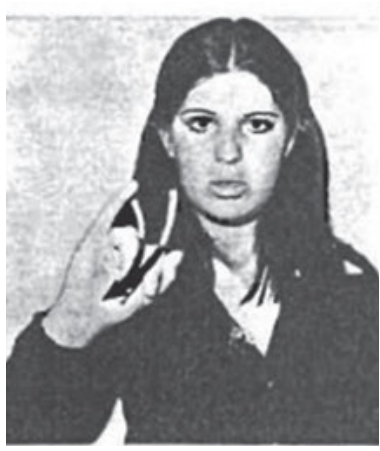

\section{White}

Cecilia Tejedor (2006) and the DILSE (2011) describe the expression of 'white' following the photo in Pinedo (2005), and indicate that it is made by touching the tip of the thumb to the middle finger of the right hand, and holding the other fingers stretched out. The hand is then brought near to the chest and extended forward as the fingers open (see two representations in Figure 9 and Figure 10). Our consultants have presented no variants with respect to this articulation, proposed by the standardising organisations of LSE. Marroquín's description is difficult to understand, and 'white' does not appear in Villabrille's dictionary.

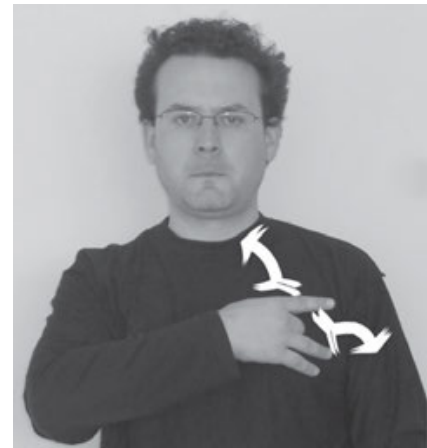

Figure 9.

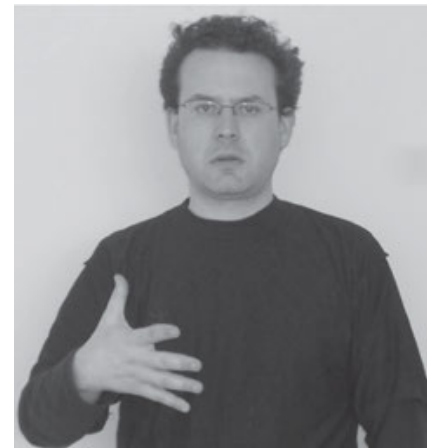

Figure 10. 
Grey

According to Fernández Villabrille (1851:70), in order to sign the colour grey "The right hand is lifted to the place of Q in dactylology, and shaken several times outwards, at the same time opening up the fingers" [S]. This does not match the photographs in Pinedo (2005) and Marroquín (1981), who both agree with the description in Vocabulario Básico: the colour grey is signed by bringing together the fingertips of the ring finger and the right thumb, and both then swipe the back of the left hand (Figure 11). As has already been pointed out, this colour does not appear in the DILSE (2011). Another variant is performed without using the left hand, making the movement in the air (Figure 12).

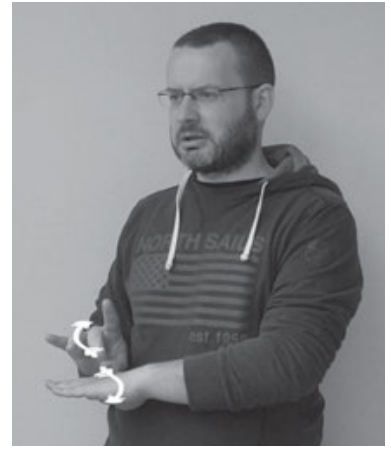

Figure 11a.

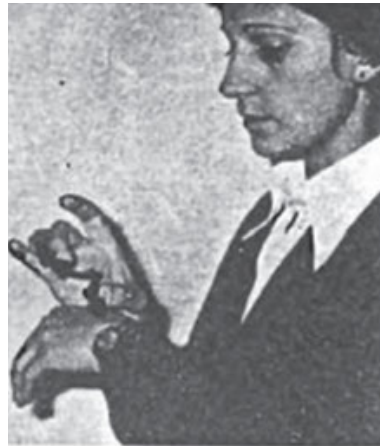

Figure 11b.

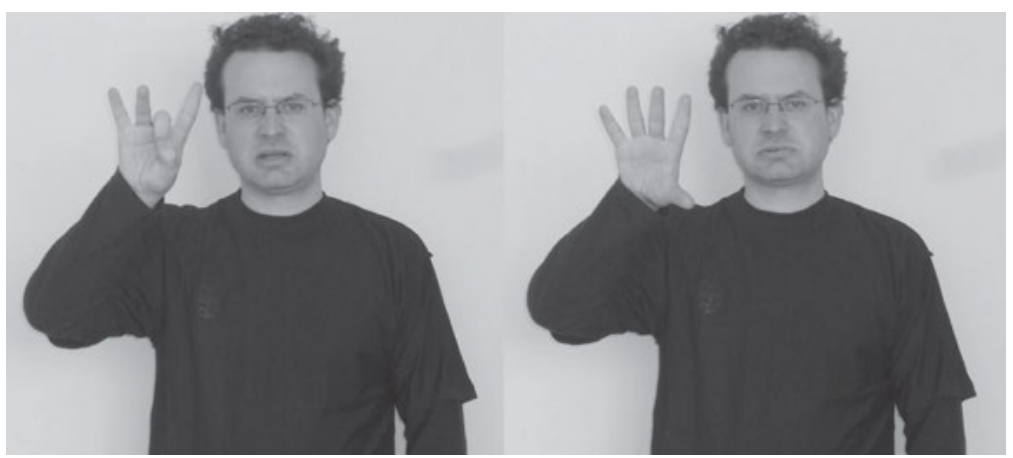

Figure 12. 
Another option is to sign with the hand under the chin, moving the fingers alternatively over the throat (Figure 13). One variant from the Canaries is performed by pretending to write in the air with a pencil (Figure 14). Yet another variant is produced with the middle finger or the index finger tapping on the extended index finger of the non-dominant hand.

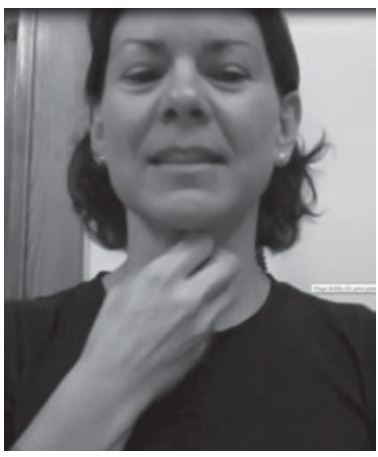

Figure 13.

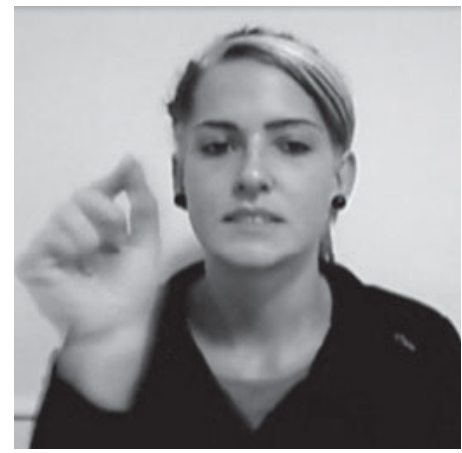

Figure 14.

\section{Brown}

This is an example of a colour term that uses the sign for an object. In the Vocabulario Básico, 'brown' is produced by resting the tips of the extended index and middle fingers of the right hand on the right cheek. In this position, the right hand moves up-and-down twice (Figure 15), and this is identical to the sign for 'chocolate'. It is also common to use the sign for 'chestnut' to refer to the colour 'brown' (Figure 16).

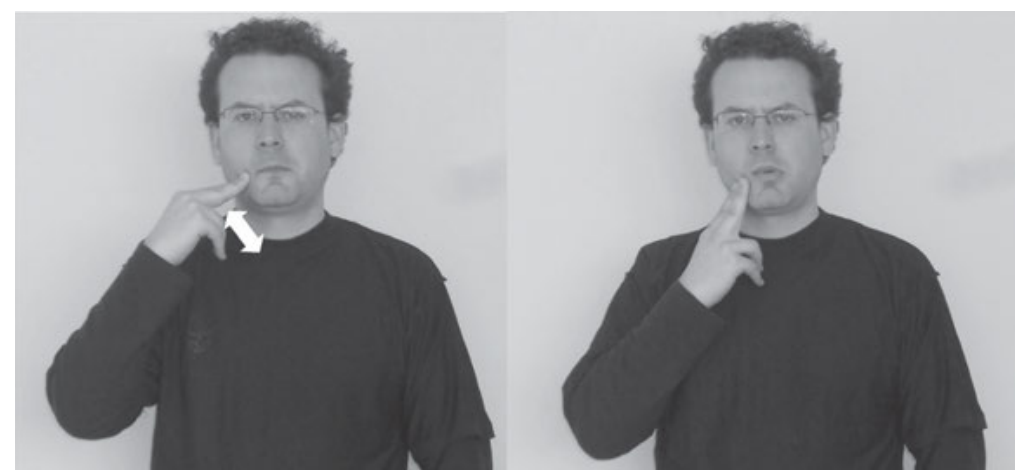

Figure 15. 


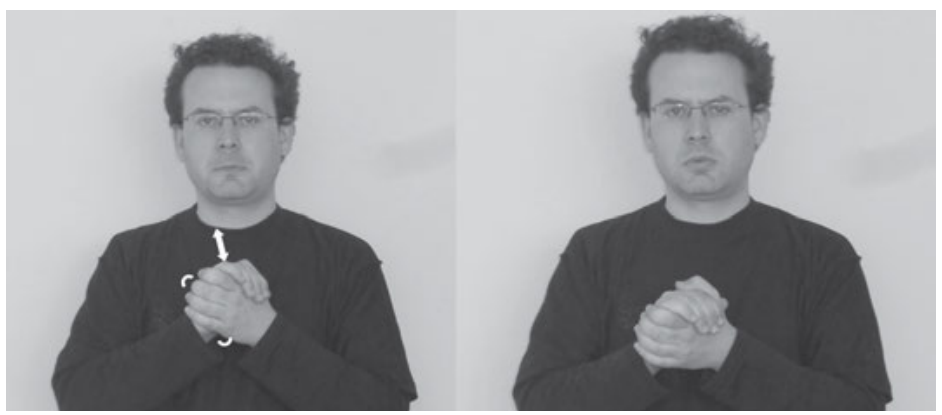

Figure 16.

A variant we have detected among our consultants is a sign in which a triangle is formed, like the roof of a house (Figure 17). Finally, our consultant from the Canaries produced the sign for brown with a sideward movement of the index and middle fingers extended and V-shaped, and with the palm towards the addressee (Figure 18). There are also other two variants in the Canaries: one is the same as the sign for black, but with the dominant hand oriented diagonally to the body, and the second has a movement involving the middle finger of the dominant hand (same as the sign for 'knife').

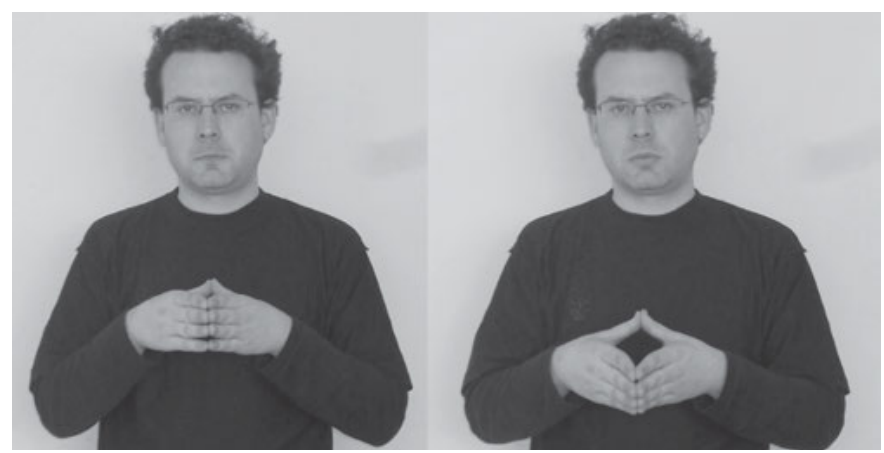

Figure 17.

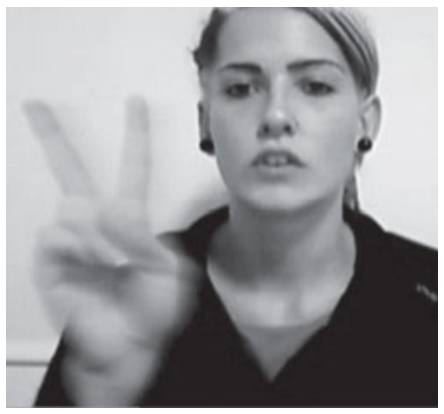

Figure 17. 


\section{Morado $^{12}$ 'purple/violet'}

The colour words purple, violet and morado signify a similar colour but have slightly different tones, which in Spanish are related to the difference of colour in the objects that the colour terms refer to. It is our impression that the LSE signers are not consciously aware of semantic differences between the various signs in use that correspond to the three terms in spoken Spanish. However, several different formal variants exist in LSE.

According to Cecilia Tejedor (2006), purple or morado "are produced with the back of the right hand under the chin, whilst fluttering the fingers" [S] (see Figure 19). A variant of this sign is one in which the hand moves downwards in a curve (Figure 20).

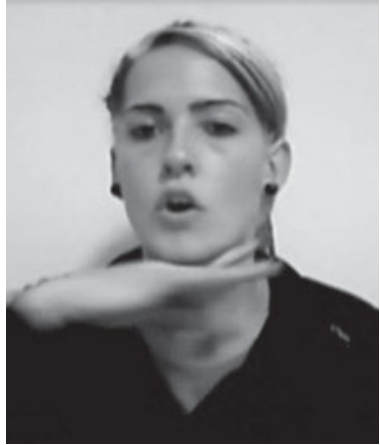

Figure 19.

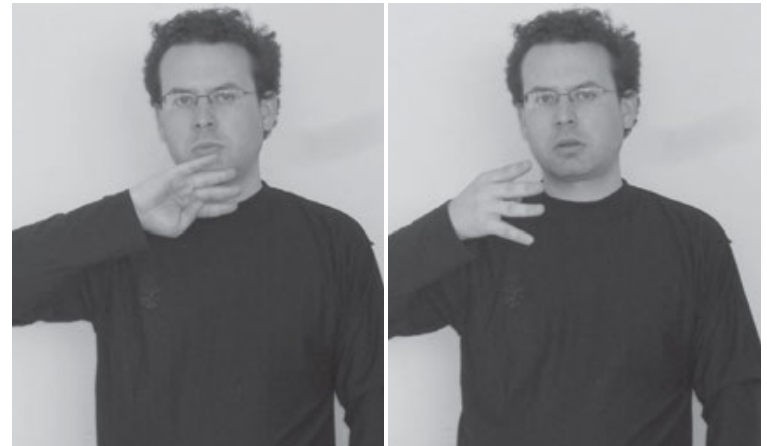

Figure 20.

Our consultants have also used the sign in Figure 21, pointing under the eye with the index finger and the middle finger.

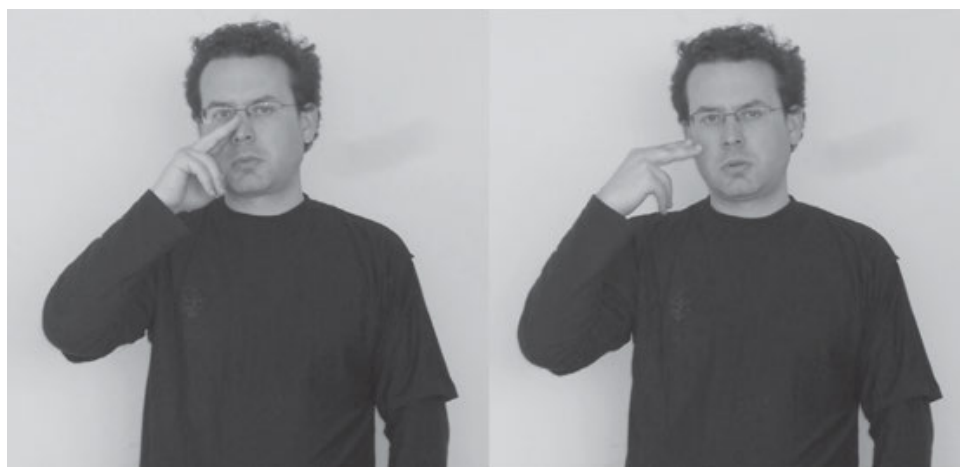

Figure 21. 


\section{Violet}

Another variant based on fingerspelling is the one performed by our consultants from the Canaries (see Figure 22). Figure 23 shows another variant of 'violet' produced by extending the index and middle finger and shaking the hand next to the body.

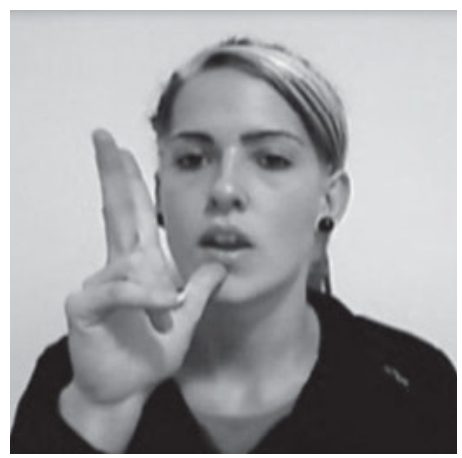

Figure 22.

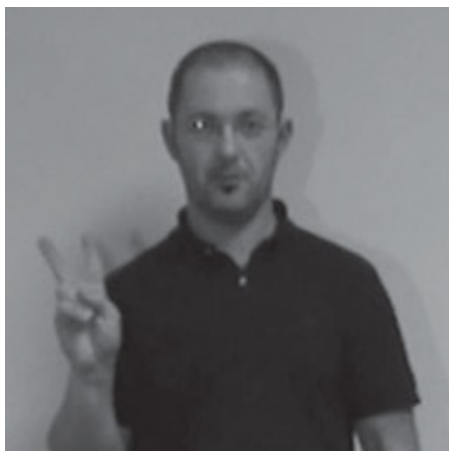

Figure 23.

\section{Orange}

The sign for 'orange' is also related to the object of the same name. Hence both, the colour and the fruit, are executed in the same way (see Figures 24 and 25), "with both hands in the shape of a claw, joining at the fingertips. In this position, hands approach and separate twice or three times" (Cecilia Tejedor 2006 [S]). This also matches the sign included by Marroquín, but a sign for 'orange' does not appear in the DILSE or the Pinedo dictionary.

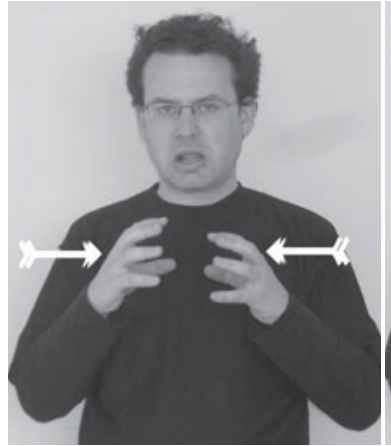

Figure 24.

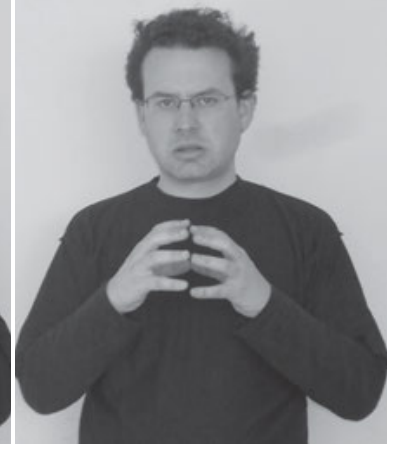

Figure 25 .

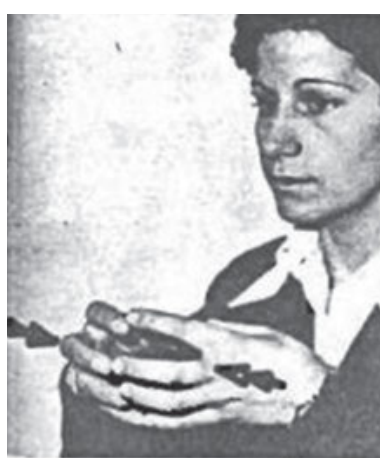


Another common variant among our consultants is performed by brushing the back of the left hand with the fingers of the right hand.

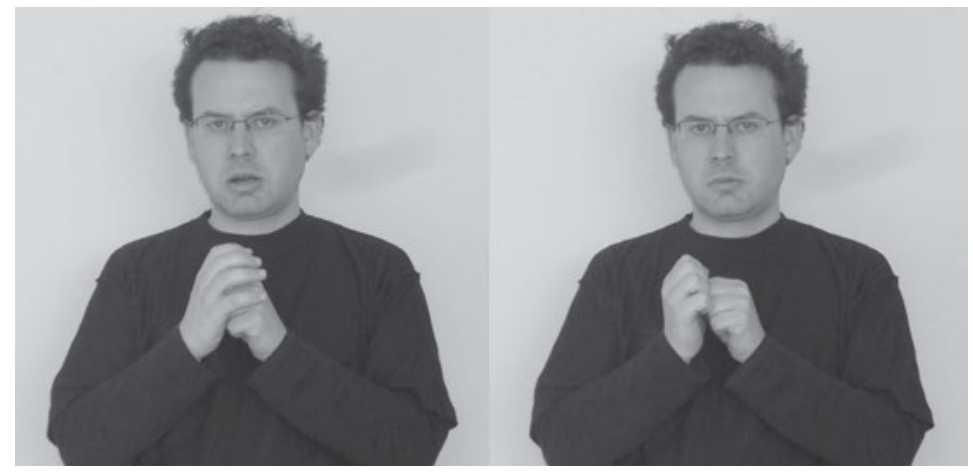

Figure 26.

Red

Red is produced by touching the lip, two or three times, with the fingertip of the right hand index finger (Herrero Blanco 2003; see Figure 27). The term 'red' is, according to the DILSE (2011), "the first colour of the spectrum $[S]$ ". All of our consultants produced virtually the same sign, with very minor articulatory differences.

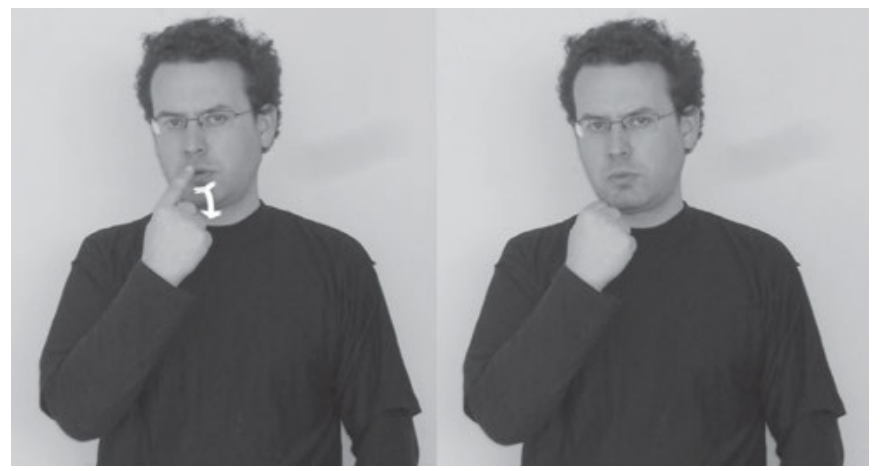

Figure 27.

In order to sign the colour 'red', Fernández Villabrille (1851:129-130) gives the following instructions: "All fingers are folded, except for the index finger which touches the lower lip" [S]. The description of Marroquín and the Vocabulario Básico is similar and says "the tip of the right hand index finger should brush over the lips [S]". 
Pink

In Spanish, the same word rosa refer to two concepts, the colour 'pink' and the flower 'rose'. Nowadays, however, the colour and the flower have their own signs in LSE. In the DILSE (2011), the sign for this colour is performed with all fingers of the dominant hand folded, except for the index finger which remains extended and moves down the face (see Figure 28). A widespread variant has a different configuration of the fingers, which are all extended instead of folded (see Figure 29).

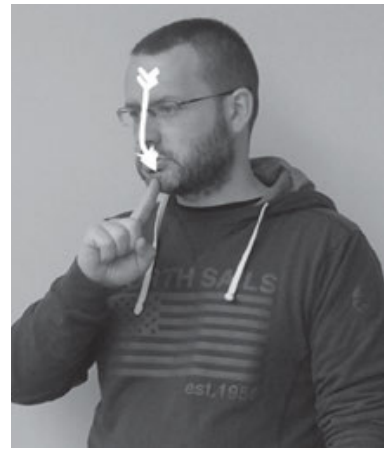

Figure 28.

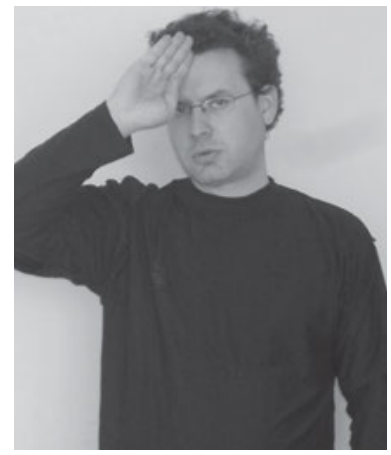

Figure 29.

In the Canaries there is another variant. The sign is produced with the hand extended and all fingers pointing upwards, with a circular motion on the cheek (see Figure 30) - the same as the sign for 'young'. One of our consultants used the sign for 'rose (the flower)', which appears in Marroquín (1981) and is shown in Figures 31a and $31 \mathrm{~b}$.

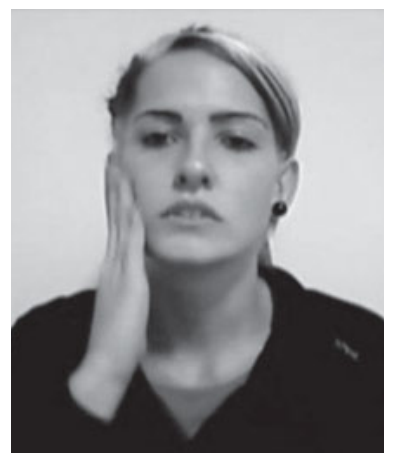

Figure 30.

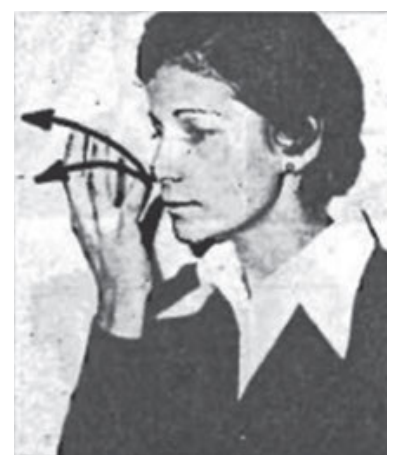

Figure 31a.

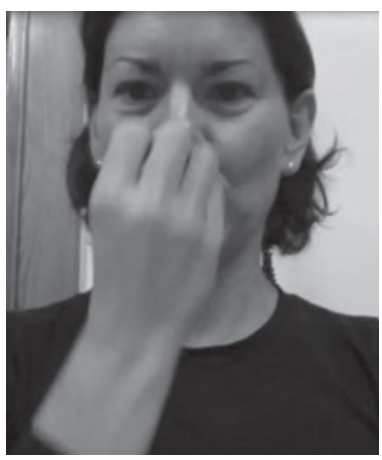

Figure $31 b$. 


\section{Green}

In order to produce the sign for 'green', Cecilia Tejedor (2006) states: "Make a V-shape as used in the manual alphabet. Then, keeping that handshape, make two circles in the air, placing the hand almost in front of the mouth [S]". This is another case of an initialised sign (from Spanish verde 'green') based on fingerspelling, and it is performed in the same sign space as 'yellow', 'red' or 'colour', that is, in the lip area. Interestingly enough, in American Sign Language (ASL) and International Sign, the sign for 'green' is formed the same way, but the initial is changed into a G (from English green).

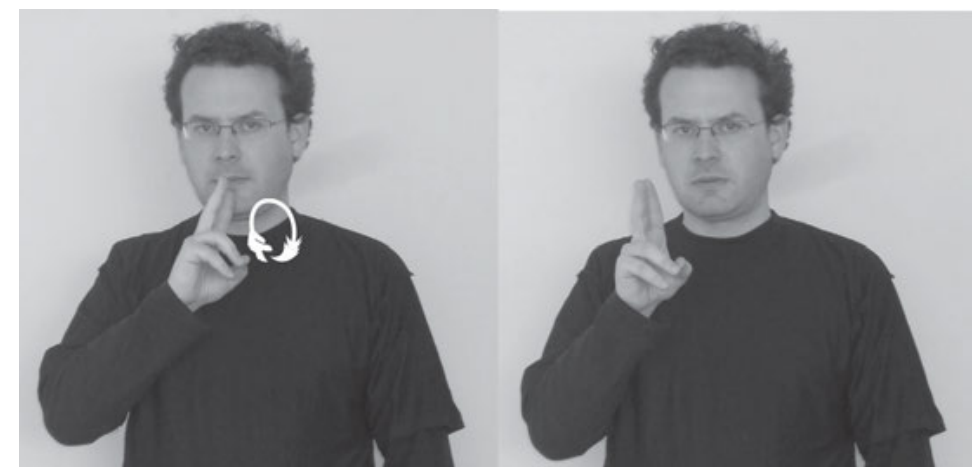

Figure 32.

\section{Black}

Black is one of the colour signs with the least variation; however, diachronically, it has changed substantially. Fernández Villabrille (1851:105) describes: "The index finger of the right hand strikes the left hand and, then, the same finger touches the nose"[S]. However, Marroquín (1975:52) describes that it is performed by "scratching the back of the left hand with the fingers of the right hand" [S].

Nowadays, both the Vocabulario Básico and our consultants signed the black colour with the index and middle fingers of both hands extended and slightly apart. All the other fingers of both hands are folded. In this position, the index and middle fingers of the right hand tap the index and middle fingers of the left hand, making a cross (see Figure 33). The variant included in the sign language dictionary of Marroquín shows the same articulation, but the point of contact is moved to the forearm, as shown in Figure 34: "the index and middle fingers touch the left forearm" (1975:52 [S]). 


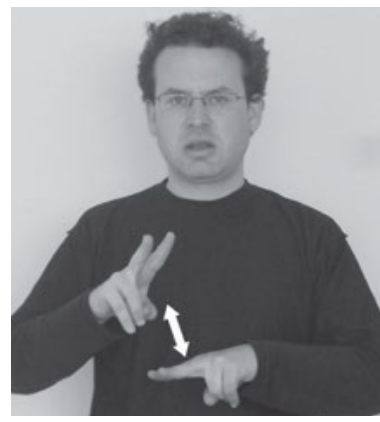

Figure 33.
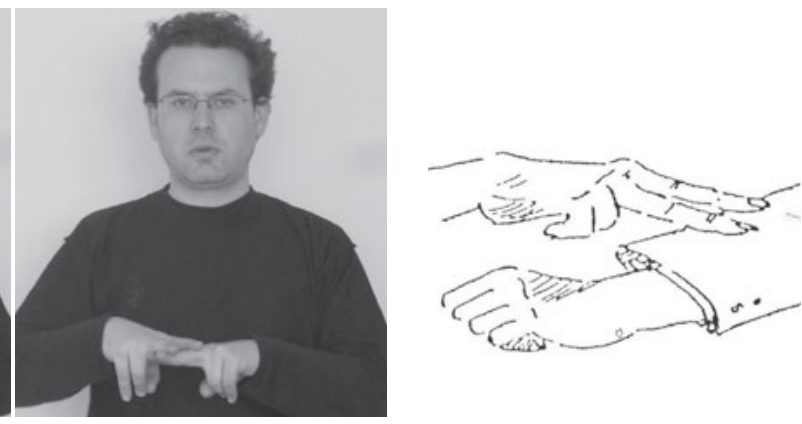

Figure 34 .

\subsection{Colour terms: Summary and discussion}

Several interesting generalisations emerge from the data on LSE colour terms discussed here, which are of interest in relation to other sign languages:

1. In the expression of colours, there is a degree of articulatory variation in the execution of signs, and these formational variants affect the aspects that constitute the sign, such as place of articulation, handshape, and articulatory movements. The issue of which phonological parameters are most affected by this kind of variation is not well-studied across sign languages, but it is noticeable in our data that these phonological variants differ most often with respect to the movement parameter. Variation with respect to movement is found in the signs for 'morado' (purple), 'blue', 'yellow'; in the latter two cases, orientation and place of articulation are also affected in addition to the movement. A handshape change occurs only once (with 'pink'), and in one case (for 'grey'), the non-dominant hand can be dropped, in which case the place of articulation is also shifted. In contrast, several phonological variants affecting the handshape parameter are documented in Indonesian Sign Language (Palfreyman, this volume). Such articulatory variation in terms of how signs are produced is discussed by Rodríguez (1992:209), who notes that "these expressive traits are continuous, and are manifested in articulatory variants on a scalar continuum, not as discrete oppositions: there are more or less well-defined handshapes, shorter or faster movements, with greater or lesser amplitude of movement at or towards the place of articulation" [S] 
2. As in other sign languages, colour terms in LSE can be grouped into several subsets depending on the origin of the sign. One subset uses initialised signs, where the handshape is derived from the manual alphabet. In LSE, the signs for the colours 'green' (V from Spanish verde), 'violet' (V from Spanish violeta) and 'blue' (A-Z from Spanish $a z u l)$ exploit the manual alphabet; interestingly, 'blue' uses a sequence of two letters from the manual alphabet in the sign. Another subset consists of colour signs that are identical to signs for objects with the same characteristic colour. In LSE, signs for the colours 'orange' and 'brown' refer to an object of that colour, sharing this characteristic with some spoken languages (e.g. the word for 'brown' in Portuguese is the same as that for 'chestnut tree'). These same types of colour signs, derived from fingerspelling and homonymous with signs for objects, are found, for instance, in Estonian Sign Language (Hollman, this volume) and in Mexican Sign Language (Hendriks, this volume).

3. Sagara and Zeshan (this volume) point out the importance of the hierarchy of colour terms proposed in Berlin and Kay (1969). Our data on colour terms show some correlation between the degree of variation of colour terms and their place in the Berlin and Kay hierarchy of colour terms. The most basic colour terms, at the far left of the hierarchy, are also among those that have the least variation in LSE, i.e. BLACK, WHITE, and RED. These three colour terms are among the signs that only have a single variant in LSE in our data.

Finally, we have noted in our research that diatopic (geographical) variants are not incomprehensible for signers coming from different areas. Evidence for this comes from our discussions with consultants. When we showed our consultants the colour signs from another region, they would comment that they also knew some people who used these signs. That is to say, signers from all regions recognised colour signs from other regions, although they might prefer to use their own variants.

\subsection{Idiomatic use of LSE colour terms}

In Spanish, there are many examples of colour-based idiomatic expressions such as ponerse colorado 'get red in the face' (lit. 'to turn coloured'), quedarse en blanco 'to be at a loss for words' (lit. 'be left white'), estar sin blanca 'to be penniless' (lit. 'to be without the white one'), verlo negro 'to be pessimistic' (lit. 'to see it black'), pasar la noche en blanco 'to spend a 
sleepless night' (lit. 'to spend the night white'), ponerse morado 'to stuff your face' (lit. 'to turn purple'), que te pongan verde o negro 'to be told off' (lit. 'that they turn you green or black'), to be dressed de punta en blanco 'to the nines' (lit. 'in white from the point'), and to find life de colour de rosa 'rose-coloured' or todo gris 'all grey'. Also, colours are qualifiers or are lexicalised in expressions such as viejo verde 'randy old man' (lit. 'green old man'), chistes verdes 'dirty jokes' (lit. 'green jokes'), novela rosas 'romantic novels' (lit.'pink novels'), and prensa amarilla 'yellow press'.

A superficial look at LSE may produce the impression that due to its visual nature and its minority status in a country where Spanish is the majority language, it might take advantage of this resource in its idioms. However, LSE makes little use of these colour-based idiomatic expressions.

In order to study this matter, we undertook field research to investigate the characteristic which makes LSE so different from Spanish. A selected group of consultants were asked to produce the signs corresponding to the concepts 'colour', 'white', 'black', 'red', 'blue', 'yellow', 'green', 'orange', 'brown', 'violet', and 'grey'. They were also asked to explain the meanings in LSE, answering questions such as "with what object do you associate these colours?; "do you remember any expression in LSE that includes a colour adjective?"; "do you relate feelings of happiness, sadness, tiredness, confusion, fury, envy, etc. with any colour?

As has already been pointed out, in Spanish, there is a great abundance of idioms based on colour terms, especially with regards to feelings and emotions. However, a search in the Diccionario Normativo of LSE (DILSE) ${ }^{13}$, produced little variety of expressions based on this creative resource. We cannot help but find it surprising that this grammatical resource, which might be easily exploited in sign languages, is so rarely used.

The DILSE defines blanco (white) as "the colour of snow or milk [S]" and Pinedo Peydró (2005 [S]) adds that it is "the lightest colour...which is the result of the combination of all the colours of the rainbow". Also, in the DILSE, it is "the colour of the light of the sun when it is not decomposed into the colours of the spectrum [S]". The colour blanco (white) stands for purity in Spanish culture; it is also said to be the colour of perfection and cleanliness, and generally has positive connotations. It is also positive in LSE. However, in our test, our consultants did not even use it in expressions as common as marca blanca 'store brand' (lit. 'white label') or as common or as often used as estar sin blanca 'to be penniless'. This phrase and no tener blanca (lit. 'not to have white') are two of the idioms in Spanish colloquial language that mean 'to be without money'. Instead of using this expression, both our consultants and the DILSE suggest another expression 
(see Figure 35) matching a similar idiomatic expression in Spanish, which does not employ colour symbolism: estar a dos velas (lit. 'to find yourself between two candles').

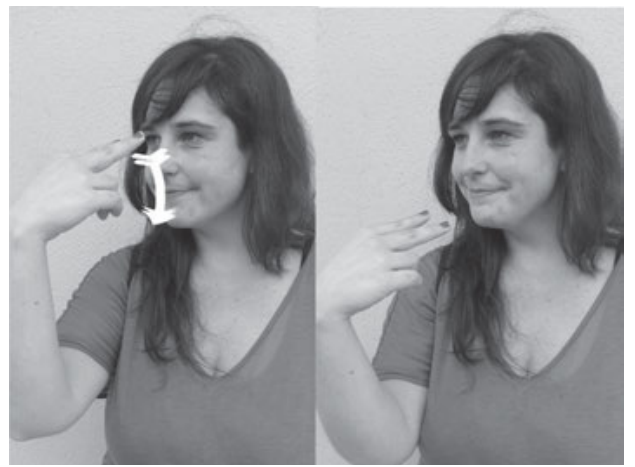

Figure 35.

The idiomatic expression quedarse en blanco, meaning 'to be at a loss for words/forget what you were going to say' was translated by MENTE APAGA 'mind went out'.

Furthermore, the colour negro (black), which in Spanish often represents authority, elegance, or formality, and is also associated with death and mystery, was clearly related to suffering and rupture by our consultants, who repeatedly used the expression corazón + negro 'heart+black' in order to indicate the breaking up of a love relationship, but in no case associated it with expressions common in Spanish such as futuro negro 'dark future' or agujeros negros 'black holes'. Pinedo Peydro (2005) defines 'black' as the colour of coal. The expression "dinero negro", which, according to the DRAE (Dictionary of the Spanish Language Academy), means "dinero clandestino e illegal" (money earned illegally) was referred to as dinero corrupto 'corrupt money' in LSE.

The Diccionario Normativo (DILSE) considers that rojo (red) is the first colour of the solar spectrum, and defines it as a colour "similar to that of blood or a ripe tomato [S]". Colloquially, in Spanish the colour red is considered emotionally intense. It is related to energy, passion and force, and it is also the colour typically used to indicate danger. In colloquial Spanish, the expression ponerse rojo 'to turn red' is often used to express shame. This was the only colour-related idiom that our consultants identified in LSE, i.e. to "turn as red as a tomato". Even though this expression does not appear in the DILSE, vergüenza 'shame' is described as "strong feelings that tend to make a person red in the face [S]". However, when our consultants were asked an indirect question related to this idiom, they did not connect this 
feeling with the colour red, nor did they associate envidia 'envy' with the colour yellow, as happens in peninsular Spanish. The dictionary compiled by Pinedo Peydró (2005) does not list any special semantic association, and defines red as "carmine colour". Fernández Villabrille (1851:129-130) accompanies the articulatory description of red with the comment "the same as a ruby" [S].

The colour amarillo is defined in the DILSE as "a colour similar to that of gold, the flower of gorse, etc [S]". In Marroquín (1981) and Pinedo Peydró (2005) the colour yellow is "the colour of gold or lemon [S]", but our consultants did not relate these items in any of their answers. They did not associate this colour with intelligence, envy or illness, as hearing people do in oral Spanish language. The expression "yellow press" was associated with "glossy papers", and pink is not connected with the expression of vitality as in ver la vida de color rosa (lit. 'to see life in rose colour'). Consultants recognised the association of 'pink' with the name of a TV programme where the lives of the "rich and famous" are debated. Other consultants, however, associated it with romance and even with honeymoon.

The DILSE defines the colour pink by its composition: "the colour resulting from mixing red and white" or "which is of a soft red colour" (Pinedo Peydró 2005 [S]). As already pointed out, the articulatory variations showed a clear distribution for some of the signers, who distinctly differentiated the sign for the colour from the name of the flower.

Green, in the DILSE, is "the colour similar to grass, the emerald, the green finch, etc [S]". Pinedo Peydró (2005) defines this colour by its composition, as "the colour obtained by mixing the primary colours blue and yellow [S]". The notion of 'to scold, to tell off' is expressed with a colour-based idiom in Spanish (poner verde, lit. 'to turn green'), but not in LSE, in which it is signed as COTILLEAR 'to gossip'. Conversely, our consultants mentioned the construction CHISTES VERDES 'dirty jokes', lit. 'green jokes' as being frequent in LSE, as it is in Spanish.

Pinedo Peydró (2005) defines gris 'grey' as the colour which is made by mixing black, white and blue. It does not appear in the DILSE, but some of our consultants linked the articulation in the throat with a resemblance to gargling. In both LSE and Spanish, the colour grey is used in idiomatic phrases such as a grey day 'a sad day', etc. Notwithstanding, in LSE 'grey' is often used as a descriptive term for e.g. an unpleasant life or a strange or boring person.

The colour blue is defined as "the fifth colour of the solar spectrum" and "the colour of the cloudless sky" by Pinedo Peydró (2005); this is the definition also found in the DILSE. According to Marroquín, 'blue' is cielo 
sereno 'calm sky'. The modifier azul in the expression príncipe azul 'Prince Charming' seemed familiar to our consultants, but they did not consider that this was an LSE expression.

As we have seen, the LSE articulation of the colour brown is associated with two objects: the chestnut and chocolate. The DILSE points out that the chestnut is "a dark brown nut covered with thick and hard skin [S]" and the sign is performed in the same way as the colour brown, by drawing a circle with both hands. However, forms for 'brown' are not found among the dictionary entries. Our consultants sometimes used the sign for 'chestnut' (the same as in Portuguese) and sometimes the sign for chocolate. Our consultants made it clear that the colloquial expressions in Spanish, where this colour is used with the meaning of 'a conflict-ridden and unpleasant situation', do not occur in LSE.

For the colour orange, the name of the fruit is used. As already pointed out, it does not appear in Pinedo Peydró (2005), nor in the DILSE but our consultants all signed it establishing this relationship between the fruit and the colour. Some associated it with the butane gas bottle commonly used in Spanish households, which is orange. They did not appear to identify the association which is present in Spanish, between the colour and a feeling of warmth and energy.

In summary, compared to the abundance of idioms in spoken Spanish based on colour terms, such as expressions of feelings and emotions that use colour adjectives, in LSE we have not found a great variety of expressions based on this creative resource, although generally LSE uses 'black' and 'grey', in order to describe feelings and idiomatic expressions. However, 'white' is never used as part of idiomatic expressions, as it is only attested when describing feelings.

In LSE, forms for pink, purple and violet are not derived from forms meaning 'the rose', 'the blackberry', or 'the violet' respectively, as happens in Spanish. Rather, one of the signs for the colour purple (see Figure 20) is iconically associated with being hit in the face, resulting in bruising in the eye area ('a black eye'). The colours 'brown' and 'orange' are expressed as lexemes related to objects, i.e the fruit orange (for 'orange'), and the chestnut or chocolate (for 'brown).

\section{The expression of quantifiers in LSE}

In order to express quantity, one of the most widely adopted strategies is the use of quantifiers, though Everett (2005) asserts than in the Pirahã language 
of the Amazon Basin, there are no numerals, nor the concept of counting. The quantifiers 'one', 'two' and 'many' are especially common crosslinguistically, and these terms constitute the minimal inventory of numerals/ quantifiers in some languages that have only a minimum of such items (Wierzbicka 1996). The use of numeral and indefinite quantifiers constitutes the primary strategy when pluralizing nouns that do not allow reduplication (Corazza and Pizzuto 1996).

Spanish Sign Language (LSE) uses a great variety of ways to express quantity. Due to lack of space, we do not analyse indefinite quantifiers, nor the different processes used for the pluralisation of nominal signs. In Fernández Soneira (2008), there is a description of all the strategies used in LSE to express quantity. In this chapter, the focus is on ways to express quantity through numerals ('two', 'twenty'), ordinals ('second', 'twentieth') and fractions ('one-half', 'one-third'). A description will be presented of numerals in LSE and of some of the associated ways to express them, such as numeral incorporation.

Our analysis includes both signs which are considered standard and other existing variants of expressions, some of which are more widespread than others and some of which are limited to specific geographical areas. This variation is integral to sign languages, as has been pointed out in previous sections. In the case of numerals, some researchers have studied the factors influencing the selection of one variant or another. Thus, for example, the research by Stamp, Schembri, Fenlon \& Rentelis (2010) on British Sign Language confirms that there are three significant factors which influence selection on the part of the signers of "non-traditional" signs for numerals: age, situation of the school and linguistic environment. This research indicated that the most relevant factor in the selection of a certain language variant is age. Younger signers habitually made use of more non-traditional signs than older signers. In the case of LSE, our consultants also assert that the use of non-traditional signs is characteristic of younger signers.

The second factor was the location of the signer's school. Those signers who went to school in their closest neighbourhood used traditional signs, as opposed to those who attended schools outside their neighbourhood, who favoured non-traditional signs. The third influencing factor was linguistic environment. The signers with hearing parents used non-traditional signs on more occasions than the signers with deaf parents. The research concluded that a change is occurring in BSL vocabulary, as younger signers are using more and more non-traditional signs. This may be due to more deaf people travelling inside their country and/or residential schools closing. 
In a study by McKee, McKee \& Major (2008) on sociolinguistic variation of sign language in New Zealand, the variants of numbers 1-20 were analysed. The main conclusion in their study is that the most determining factor for a certain variant is age followed by region and then gender. They also state that " $[t]$ he contemporary numeral lexicon in NZSL appears relatively unstable, with several variants for a single number co-existing in common usage" (ibid 2008:297). LSE, on the contrary, has a rather stable numeral system; the variations in the formation of signs we have found affect the orientation or place of articulation parameters of articulation, but the other formational parameters of the sign are kept constant across variants. We have also detected that in younger signers there is a tendency towards articulatory reduction of numeral signs (such as, the use of only one hand for traditionally bi-manual signs).

In LSE, the existing variants are found in numerals from 11-15 and in the tens, hundreds and thousands. In this case, as also pointed out in the studies carried out by Stamp et al. and McKee et al., the factors of age, schooling and gender, as well as the sociocultural status of the signer, affect the selection of a certain variant.

The selection of the numeral signs analysed in this study is influenced by two factors above all else: age and the geographical location of the signer's school. As will be seen in the following, the Galician variant of LSE has a specific numeral system for the tens, that is related to the School for the Deaf located at Santiago de Compostela, and which is used most commonly by adult signers. Some of our consultants also point out the existence of articulatory differences when performing these signs, which are motivated by the gender of the signer.

In order to obtain this data, we have relied on different sources such as dictionaries, specialised bibliographies, sign language teaching materials etc., with a view to comparing variants. We have also included information submitted by consultants, all of whom are LSE users: four deaf people and four interpreters (as stated in the Table 1) from Galicia, Murcia, Madrid and the Canary Islands. Following the model used by Fuentes (2000), the researchers asked the consultants to sign, in LSE, a series of numerals presented to them in writing with Arabic notation. The consultants were asked to sign each variant which they knew, and to explain the rules governing such variants. All of the responses in LSE were recorded by experienced researchers using a video camera and a high-definition camera against a light background, which showed the outline and the movements of the consultant clearly. 


\subsection{Cardinal Numerals}

LSE uses a decimal system, i.e. ten basic signs for the cardinal numerals that can be counted on the fingers. This is due to the fact that the articulatory possibilities only allow the iconic expression for the numbers one through ten. These numbers are signed by extending the fingers upwards, starting with the index finger of the dominant hand. When the number five is signed, the signer moves from the active hand to the passive one and starts counting again, extending the fingers, while maintaining the handshape of the number five on the other hand.

Zero and the numbers one through ten show articulatory variants (see Figures 36 and 37 for an example). Some of them involve the changing of only one parameter, but they do not affect the comprehension of the sign. Both in the articulation of the cardinal numerals shown in the different sources, and in the signing of our consultants, there is variation in the orientation of the palm of the hand, which can be facing the signer, as occurs in the Diccionario de la lengua de signos española (Pinedo 2005) and in Mil palabras con las manos (Cecilia Tejedor 2006), or facing the interlocutor, as in sources such as Sematos (2009) ${ }^{14}$ and in Gramática didáctica de la lengua de signos española (Herrero Blanco 2009). Herrero Blanco asserts that, for one through ten, the prevailing tendency is for the palm of the hand to face the signer, and she adds that the variants are regional: "Note that the variation in orientation cannot be considered incorrect, as it is used in some regions of LSE [S]" (Herrero Blanco, 2009:176). Two of our consultants indicated that, occasionally, the same signers may use both orientations depending on the context. If, in the communicative situation, the two signers are situated face-to-face, the numerals are signed using the "standard" signing, with the palm facing the signer. However, if the signers are some distance apart, the signs are made with the palm facing outwards, as this position offers a better view of the articulation.

Another variant that has been found in the signs six through ten is the alternation in orientation of the palm of the hand. That is to say, the number five is performed with the palm facing the signer, and the numbers signed with the other palm facing outwards. Among our consultants, one individual always uses this alternation, but another individual claims to have seen this same phenomenon in signers from the autonomous region of Valencia, whereas signers from Madrid perform the numeral signs mainly with the palm facing the signer. 


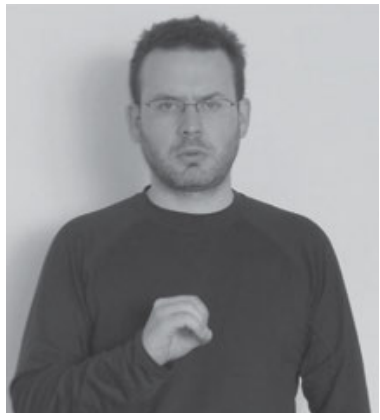

Figure 36. ZERO (a)

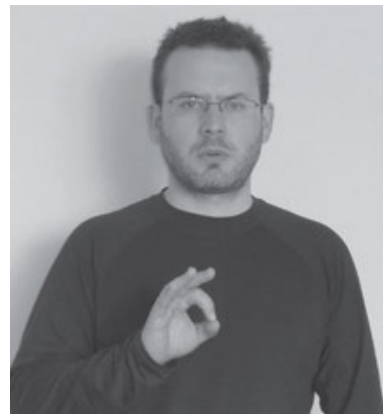

Figure 37. ZERO (b)

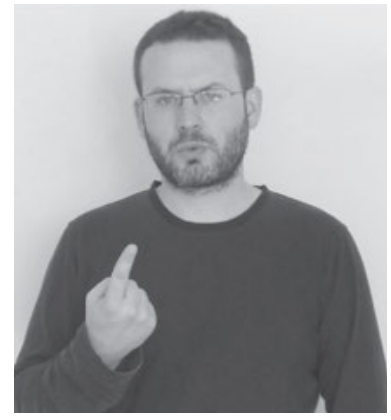

Figure 38. ONE

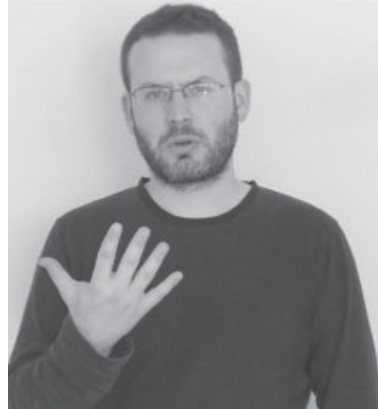

Figure 39. FIVE

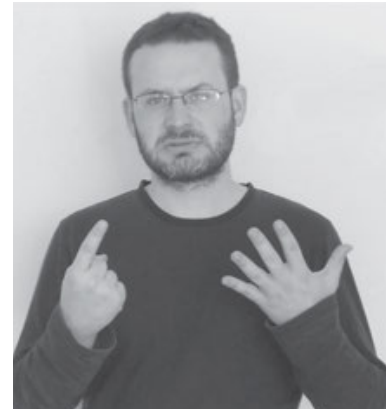

Figure 40. SIX

There can also be variation in the place of articulation: the signs are always performed in front of the signer, but the hand can be situated at face level, at chest level or at one side of the signer's body.

Another possibility of articulating cardinals six through ten is with one hand only. In this case the signer uses only the dominant hand, moving the five handshape from his/her chest towards the neutral signing space and then signing the digits that must be added to five in order to indicate the intended number, e.g. one digit for 'six', as shown in Figure 41. ${ }^{15}$

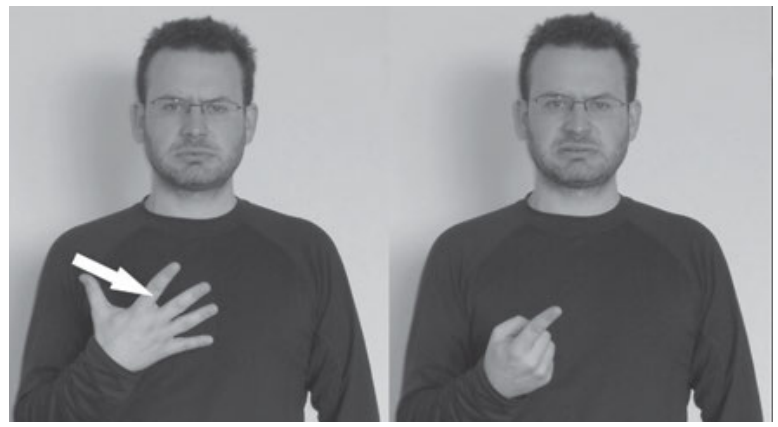

Figure 41. SIX (one-handed form) 
From number ten onwards, the articulation of the numerals is rather uniform, making use of the special characteristics of LSE, where the signs involve path movement through the sign space. First, the number corresponding to the tens is signed, and then the sign for the unit (e.g. $3+6=36$, shown in Figure 42), moving the sign through the space from left to right if the signer is right-handed. Even though the orientation of the palm is facing the interlocutor in the case of ten through 15 , in the subsequent numbers the orientation is not always the same.

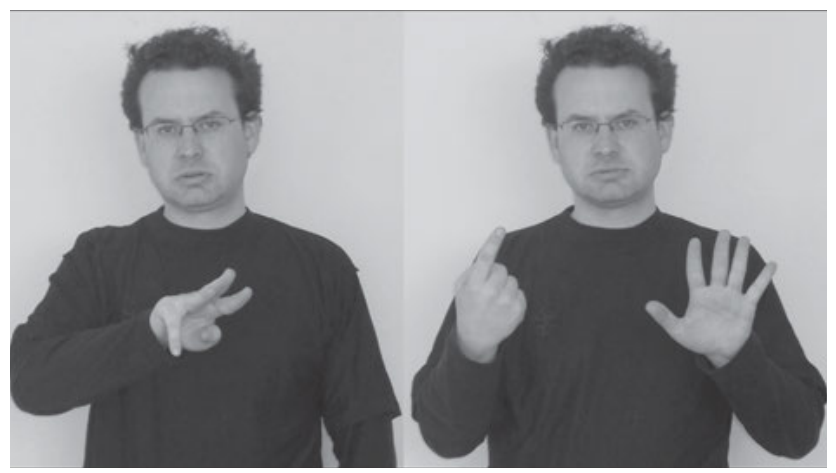

Figure 42. Number 36

Signs for numbers 12 through 15 start out with a closed handshape and then show as many numbers as must be added to ten to form the number intended, e.g. two fingers for ' 12 ', as shown in Figure 43 below.

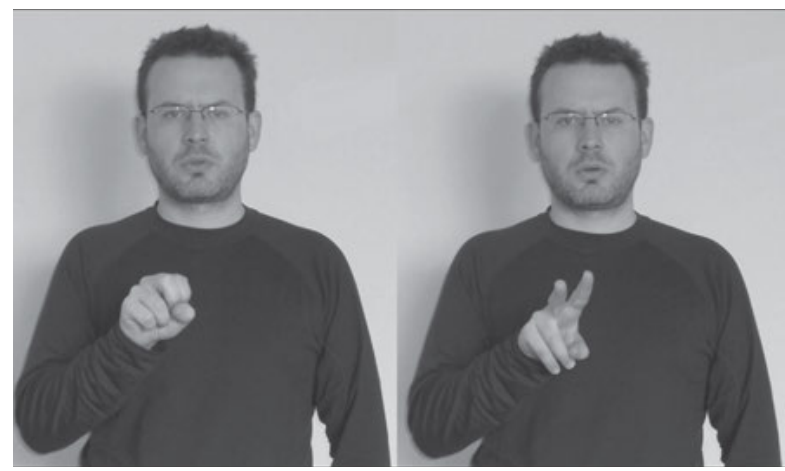

Figure 43. Number 12

One of our consultants claims that this is the only articulation used in some regions, such as in Madrid, whilst other regions, such as Murcia, use the form mentioned above, with path movement of the hand through the sign space. 
The numbers 16 through 20 are made differently, using a strategy specific to these numbers and not present in the other tens. Figure 44 shows the sign for 16, leaving only the index finger extended (16), and for numbers 17 to 19 additional fingers are extended (Pinedo Peydró 2005; Cecilia Tejedor 2006; Herrero Blanco 2009). There is a variant, included in the Sematos dictionary, where the palm of the non-dominant hand is facing towards the interlocutor. In informal contexts, the articulation of these signs can be reduced; they then become one-handed, as can be seen in Figure 45. These non-traditional signs are typical of younger signers and have not been documented in adult signers.

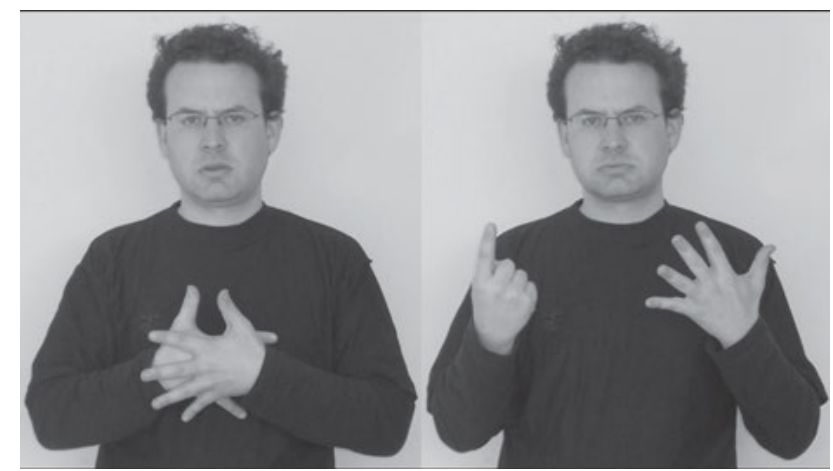

Figure 44. Number 16

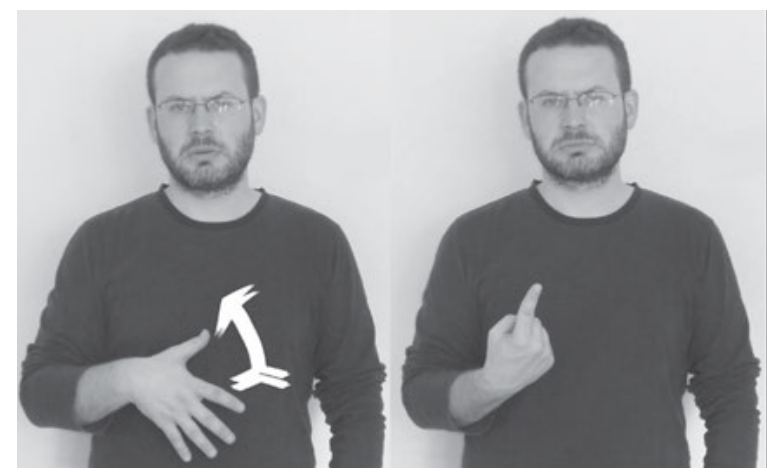

Figure 45. 16 (one-handed form)

From 20 through 100, the signs for multiples of ten are articulated sequentially, signing both digits with a change in palm orientation (Figure 46). One of our consultants points out that variants exist in the articulation of some of the tens. For example, in Madrid, the number 50 can be signed without changing the orientation of the palm of the hand, i.e., both the number five 
and 'zero' are signed with the palm outwards, with a slight movement of the hand towards the right (in right-handed signers).

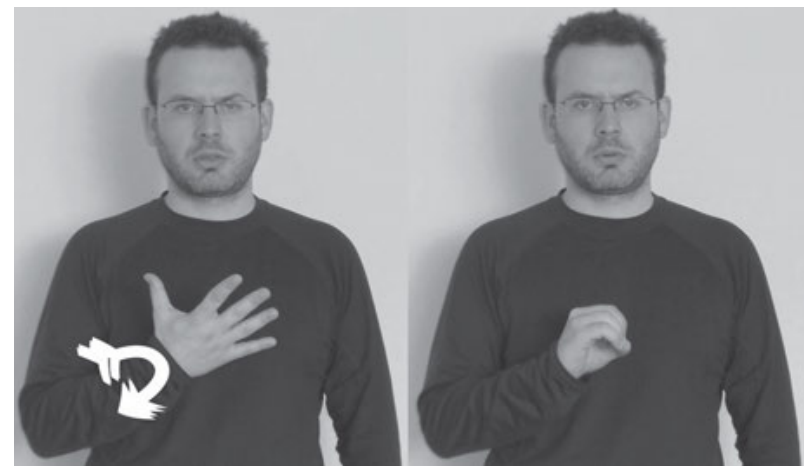

Figure 46. Number 50

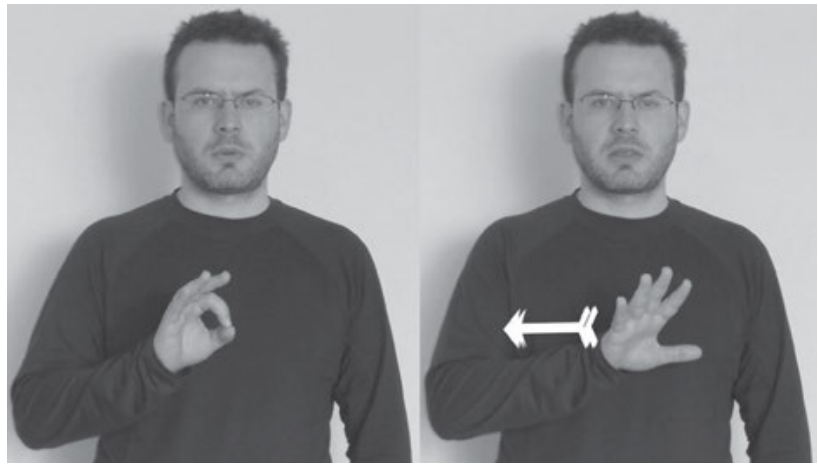

Figure 47. Number 50(b)

As for number 100, the standard articulation is with the palm outwards, firstly signing the number 'one' in the centre of the neutral signing space, and subsequently the hand adopts the handshape of 'zero', which is repeated twice, with a straight movement towards the right-hand side. We have documented two other possibilities of expression that are rather widespread among signers. One is the variant described above, but with a simplified articulation: the extended index finger is moved upwards and downwards in a straight diagonal line, changing the handshape so the hand takes on the 'zero' shape. The second variant consists of an initial handshape with all fingers in a fist (with the palm facing the signer), the wrist is turned, followed by a final handshape with extended index finger (palm facing downwards). 


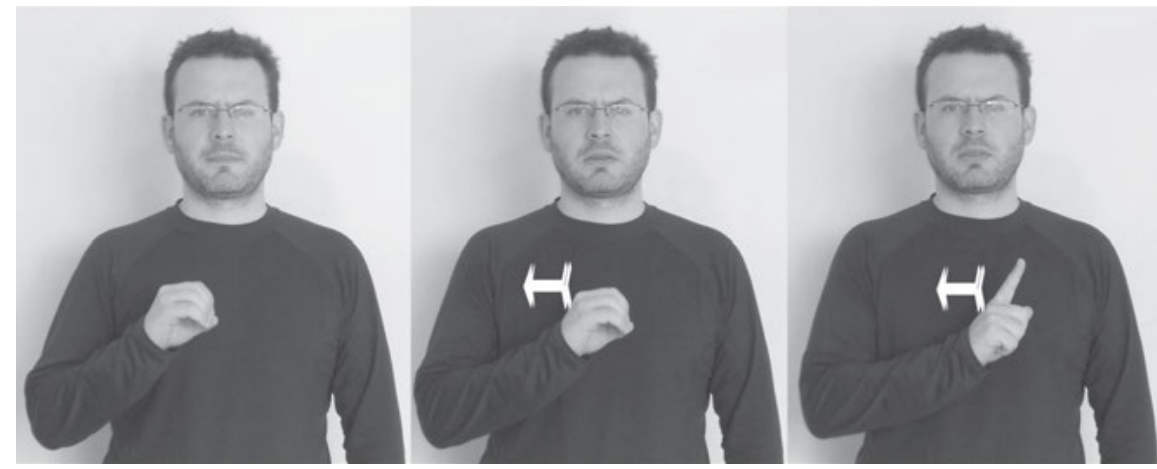

Figure 48. Number 100

The usage of these variants depends on the discourse context. The first two are used principally when the number 100 is signed, however, the third option tends to be preferred when intermediate numbers are signed (e.g. 101, 136). Furthermore, the standard sign is also more common in formal registers, in some types of discourse such as presentations, due to the fact that its articulation is clearer and more visible.

It is in this part of the numeral paradigm, with multiples of ten from 20 to 100 , where we find diatopic variants. The Galician regional variant performs all the multiples of ten with a different handshape, but in all cases both hands are used and they touch each other in front of the signer's body. This system is of great interest because it is vigesimal, and as Sagara \& Zeshan point out in the introduction to this volume, vigesimal numeral systems are very rare in sign languages.

The vigesimal nature of this system is evident when we consider the several component sub-series that it consists of. First of all, in the numerals $20,40,60$ and 80 we have full regularity in the system: 20 is the basic number, where no fingers are extended and we merely have two fists touching at the knuckles. In the next higher member of the sub-series, 40, there is one "level" of extended fingers, with index fingers and thumbs forming a ring. In 60, another "level" has been added, with the middle fingers touching too. Finally, all fingers touch at the tips in 80 , which completes this sub-series. Note that when moving from 60 to 80, two sets of additional fingers are added $^{16}$, the ring fingers and little fingers, presumably because adding only the ring fingers would be hard to distinguish from adding both ring fingers and little fingers - these two formations would look very similar. 
Colours and Numerals in Spanish Sign Language (LSE) 105

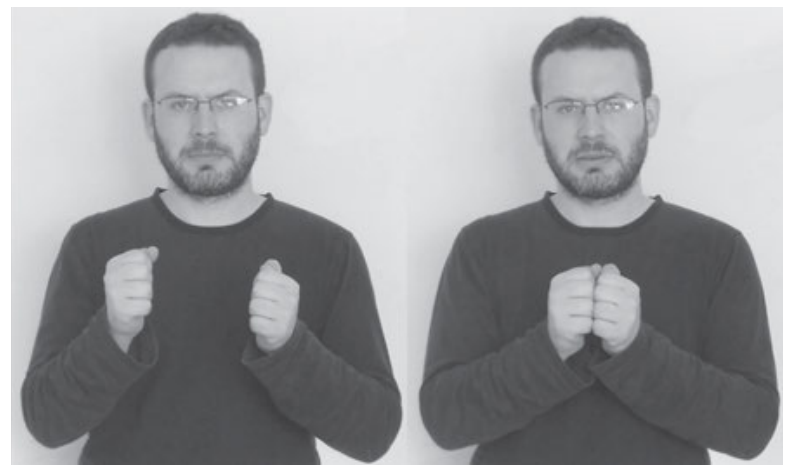

Figure 49. 20 (Galician variant)

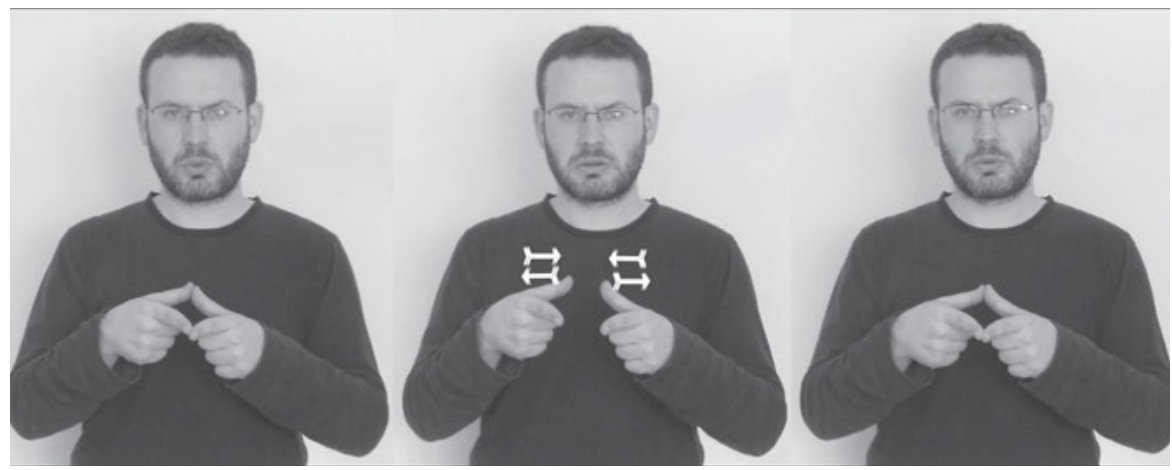

Figure 50. 40 (Galician variant)

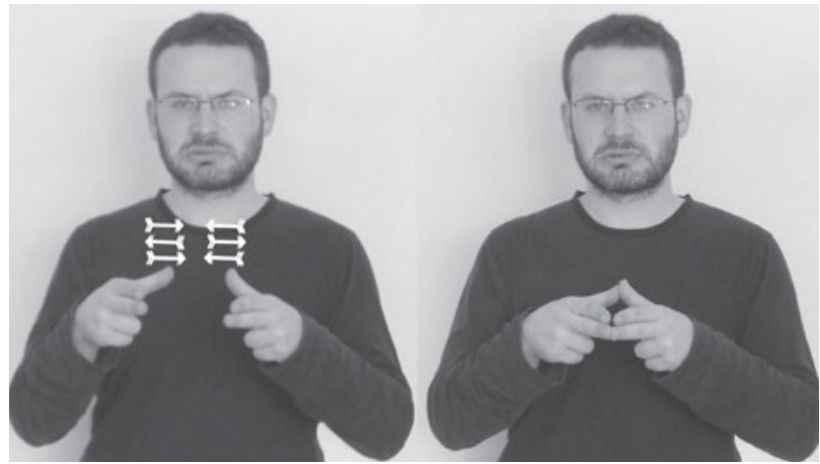

Figure 51. 60 (Galician variant) 


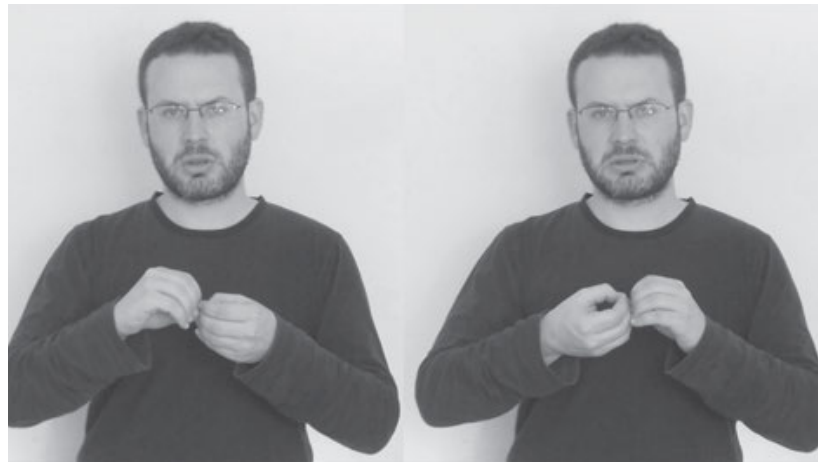

Figure 52. 80 (Galician variant)

The sub-series consisting of 30 and 50 is characterised by a prominent finger extension with respect to the nearest lower numeral. While each additional "level" in the 20 to 80 sub-series is two-handed and adds another twenty to the number, extending an additional finger is one-handed and, conceptually, adds half of twenty. This is seen most clearly in '50', which looks much like ' 40 ' except for an additional extended finger, which adds 10 to the number 40. For ' 30 ', it seems that an additional thumb extension is made visually more obvious by index finger pointing to the extended thumb. The other fingers remain folded away as they are when signing ' 20 '.

From '70' onwards, the regularity of the system breaks down, and in the present-day system, ' 70 ' and '90' are not part of a regular sub-series (although ' 70 ' does have index finger extension), and neither is ' 100 '. In a sense, the hand "runs out of fingers" because once ' 80 ' is reached, no further fingers are available for the purpose of additional finger extension. Interestingly, a system consisting of several sub-series and a degree of irregularity is also characteristic of the only other attested vigesimal numeral sub-system in Mardin Sign Language from Turkey (Zeshan et al. 2012).

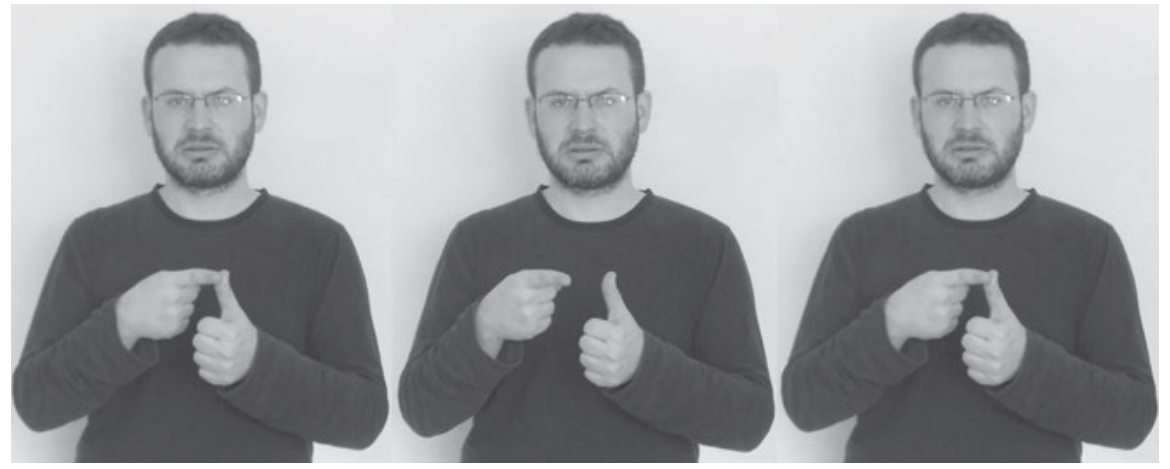

Figure 53. 30 (Galician variant) 


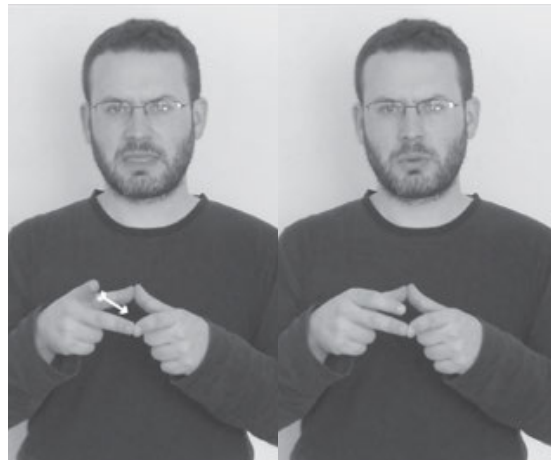

Figure 54. 50 (Galician variant)

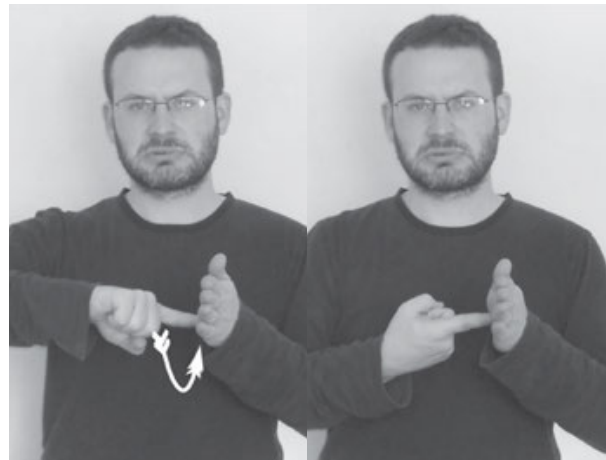

Figure 55. 70 (Galician variant)

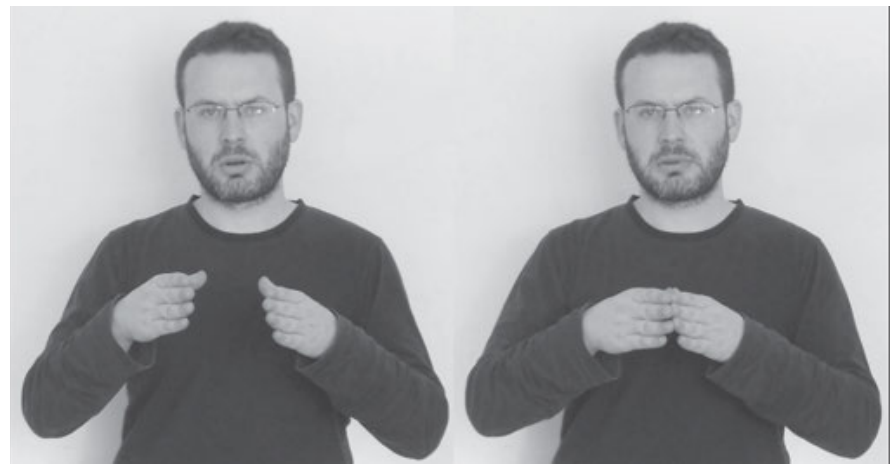

Figure 56. 90 (Galician variant)

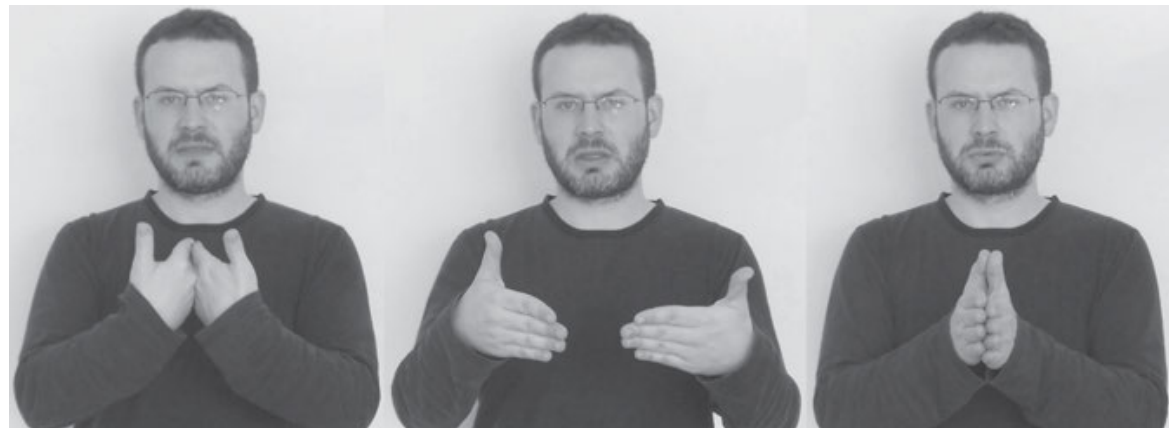

Figure 57. 100 (Galician variant)

Some of our consultants point to the existence of variants within this subsystem of multiples of ten, especially for ' 60 ' and ' 70 '. The variants seem to be due to the fact that at the residential schools where they were boarders, 
the signs used by men and by women are developed in a different manner. Women reverse the signs, as they used the ' 70 ' sign to indicate the number ' 60 ', and the other way round, the sign ' 60 ' to express number ' 70 '.

Some of these aforementioned variants are also included in LSE handbooks, namely the signs for the numbers 20 (Pinedo Peydró 2005:953 and Sematos 2009), and 30 and 40 (Pinedo Peydró 2005:954). Such widespread use of these variants may be due to ease of articulation, which allows for speed in signing. They are not only used for the tens, but also for the rest of the numbers, in the case of 20 through 29.

With regard to the thousands, we have found three variants: the most common and the one which appears in all three handbooks, ${ }^{17}$ has two parts, the numeral for the multiple of 1,000, signed with the dominant hand, followed by 'thousand' (Figures 58 and 59). There are variants of this sign where the initial handshape for the multiple (e.g. two extended fingers for ' 2,000 ') carries over to the second part of the sign, so that only the tips of the selected fingers make contact with the non-dominant hand.

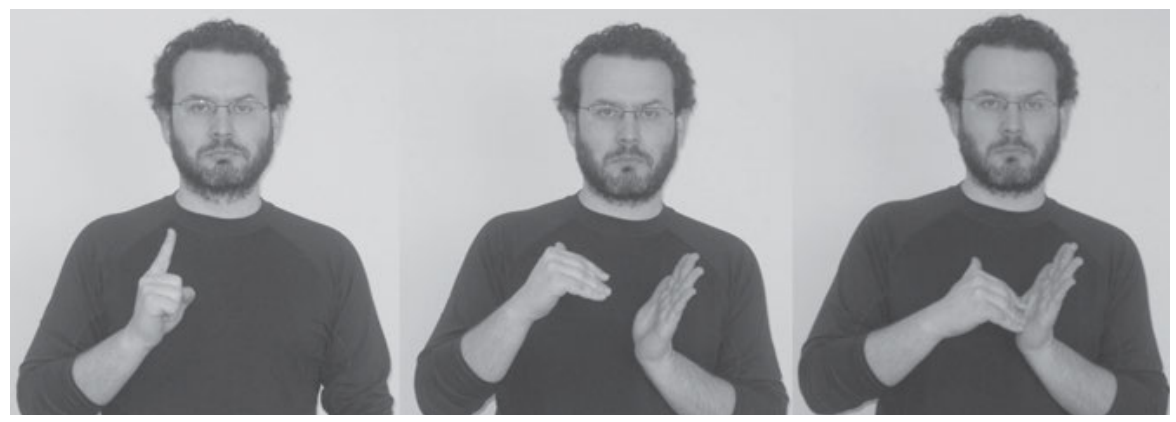

Figure 58. 1000 (a)

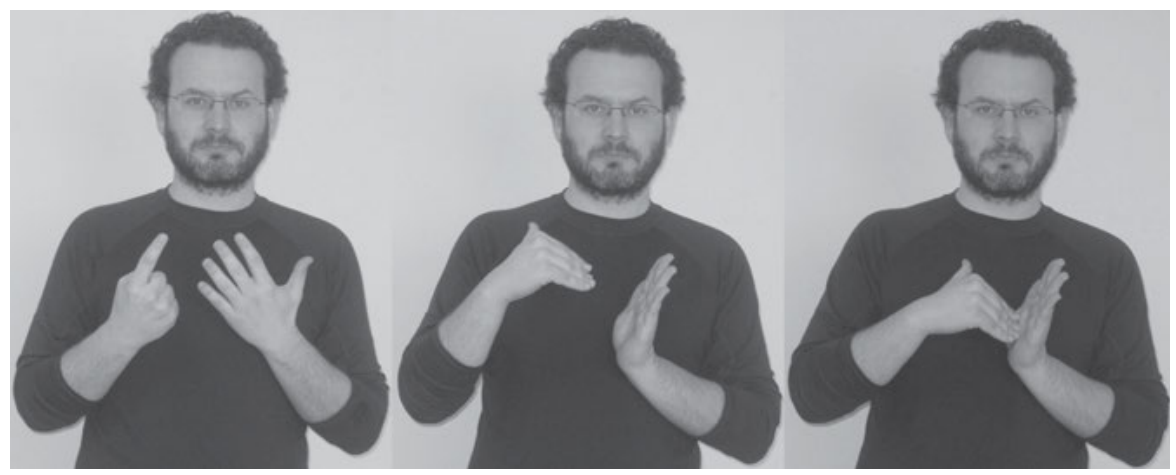

Figure 59. 6000 
Another variant, which can also be found in Pinedo Peydró (2005:956), is produced with the dominant hand only (Figure 60), and the third variant is shown in Figure 61. Both signs are instances of numeral incorporation and thus expressing the multiples of thousands involve changing the numeral handshape of the sign (see Section 4.5 on numeral incorporation).

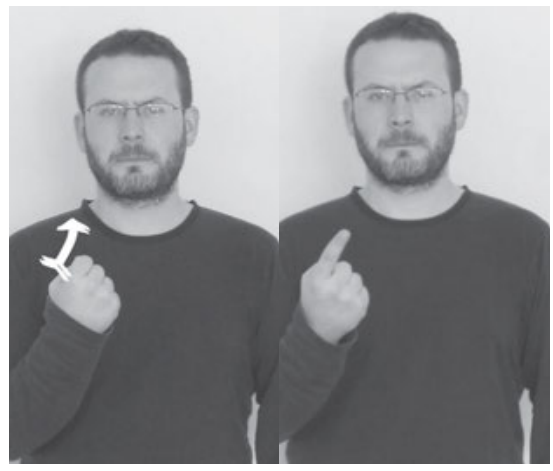

Figure 60. 1000 (b)

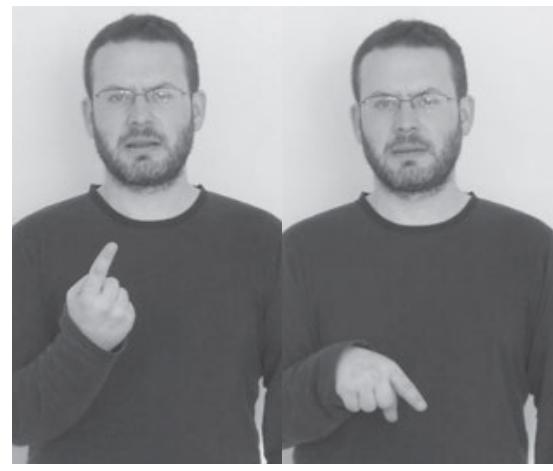

Figure 61. 1000 (c)

In common usage, the signs described above are often replaced with signing a sequential series of digits in the space from left to right if the signer is right-handed. This strategy is often used with dates, mainly when referring to years (for example, '2014').

A separate lexical sign exists for the number 10,000 (see Figure 62). This variant can also be used to sign the number 5,000, in which case it is onehanded. However, our consultants believe that this is used exclusively in informal contexts.

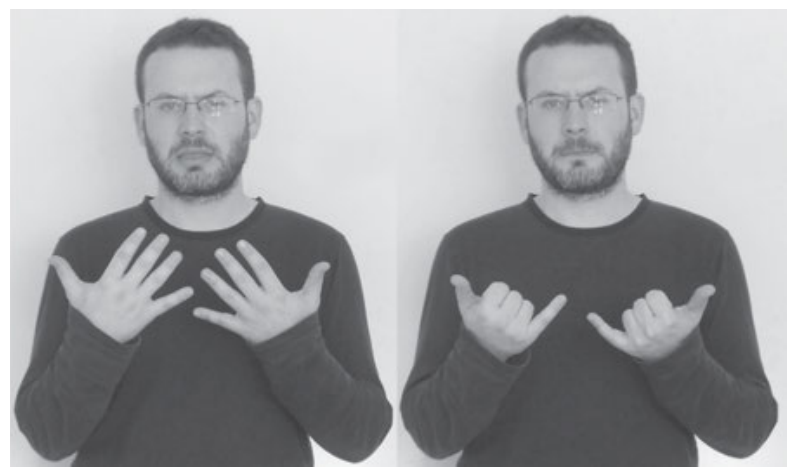

Figure 62. 10,000

Similarly, several variants are found for $1,000,000$. The standard variant is included in Pinedo Peydró (2005:956), Cecilia Tejedor (2006) and in Herrero 
Blanco (2009:176) and is shown in Figure 63. Sometimes, in order to indicate just 'million', without expressing a particular multiple, the second part of the sign with the hands touching each other can be produced on its own.

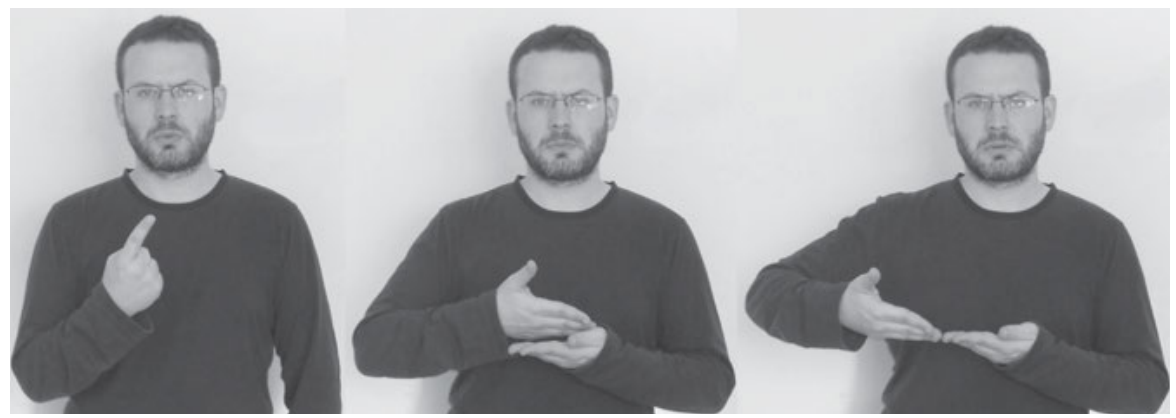

Figure 63. 1,000,000 (a)

Another common sign for 'million' (Figure 64), has an emphatic variant (Figure 65). The emphatic variant is used in contexts where excitement is shown, such as situations where the earning/winning of money is involved.

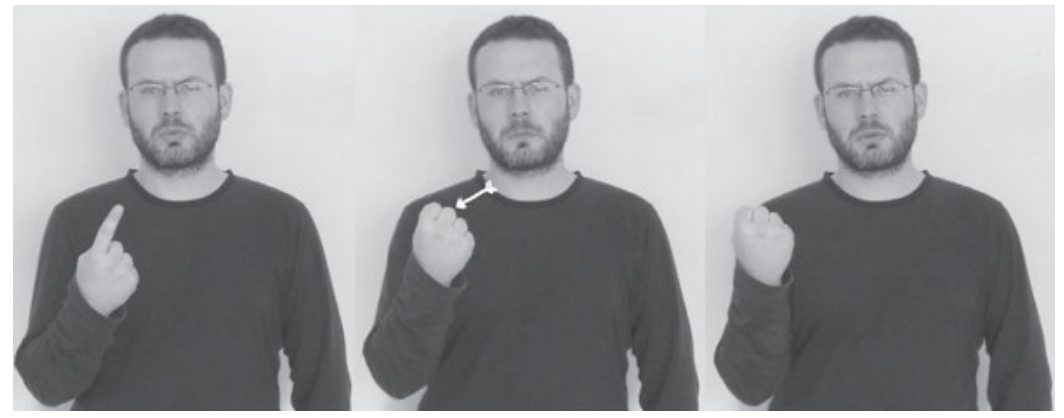

Figure 64. 1,000,000 (b)

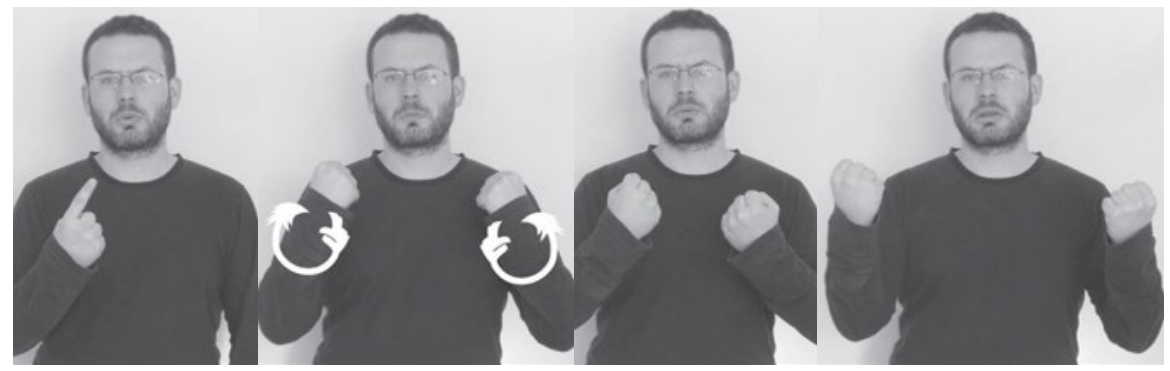

Figure 65. 1,000,000 (c) 
4.3. Fractions

In LSE, the following strategies to express fractions are found:

1. There are two signs to express 'percentage'. They are similar, but one uses both hands (see Figure 67) and the other uses only one hand (see Figure 66).

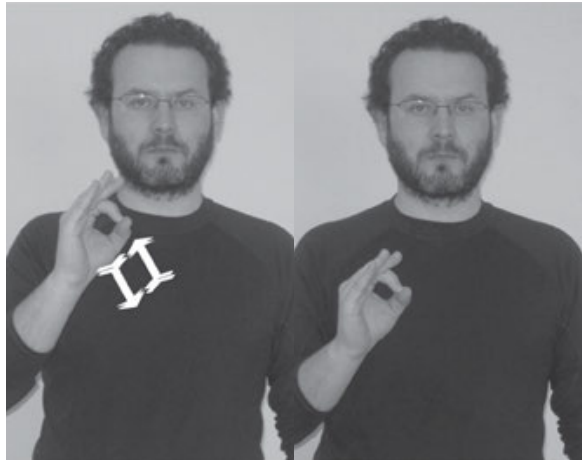

Figure 66. \% (one-handed)

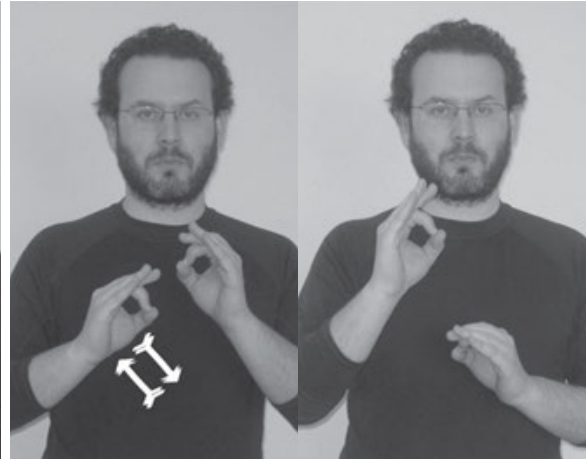

Figure 67. \% (two-handed)

(a) I JUST BUY CLOTHES PRICE 50 percentage DISCOUNT 'I bought some clothes, at $50 \%$ of their usual price.'

2. There is a strategy to represent decimal numbers such as 1.5 .

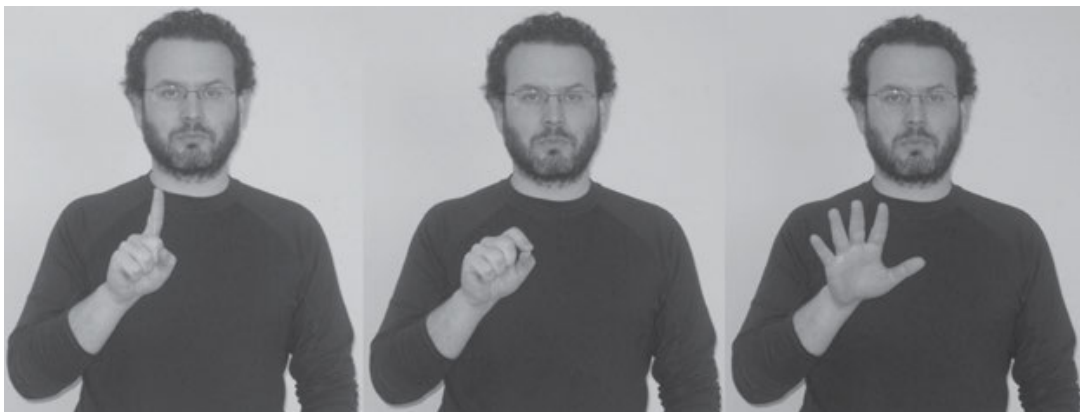

Figure 68. 1.5

(b) I CAR BUY BRAND PEUGEOT NUMBER 1.6 'I bought a car with a 1.6 engine. 
As is the case in other sign languages, these are strategies that are strongly linked to written language. They are not very productive numeral subsystems, and they are used in highly specific contexts, such as reference to mathematical numbers.

3. Figure 69 represents the sign which is used to express 'half' or 'halved'.

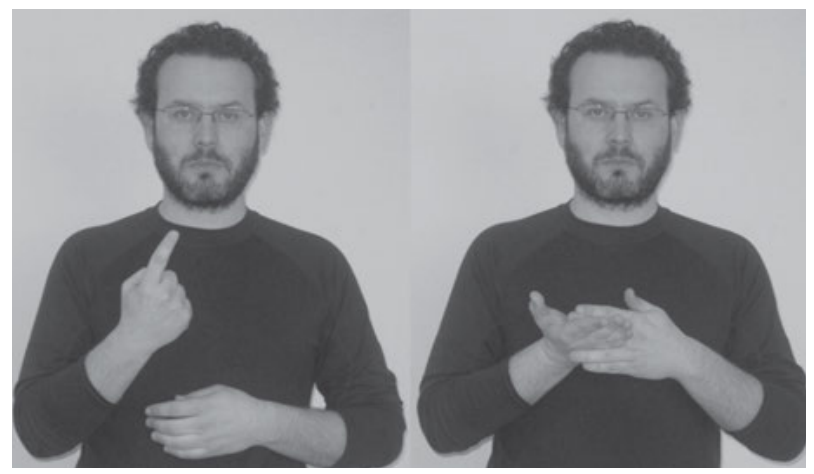

Figure 69. HALF

(c)

I BUY CAR THIS[LOC X] CHEAP PRICE HALF ANOTHER [LOC Y] CAR

'I bought a very cheap car, for half the price I would have paid for another car.'

*cejj: lowered eyebrows

\subsection{Ordinal numerals}

In LSE, there are ten basic signs for the ordinal numerals from one through ten. The ordinals are normally signed in a similar way as the corresponding cardinal paradigm, but with a wrist turn. The initial orientation has the back of the hand facing the signer, and the sign finishes with it facing the speaker. From 11 onwards, it is common to sign the object which is being talked about first, and then a cardinal numeral is used.

In addition to numerical and order information, these signs can also indicate distribution. In such cases, the orientation of the hand can be changed for the ordinal number, which can be signed horizontally. When these numerals are used in the context of signs with a certain visual-spatial orientation, the orientation of the hand may vary in order to identify the objects being 
referred to. This happens in the case of the signs DOOR or FLOOR. If the signer wishes to indicate, for example, the door on a specific floor where he/ she lives, it will be done with the finger tips pointing upwards, but to indicate on what floor he/she lives, the hand will be kept in a horizontal position with finger tips pointing sideways.

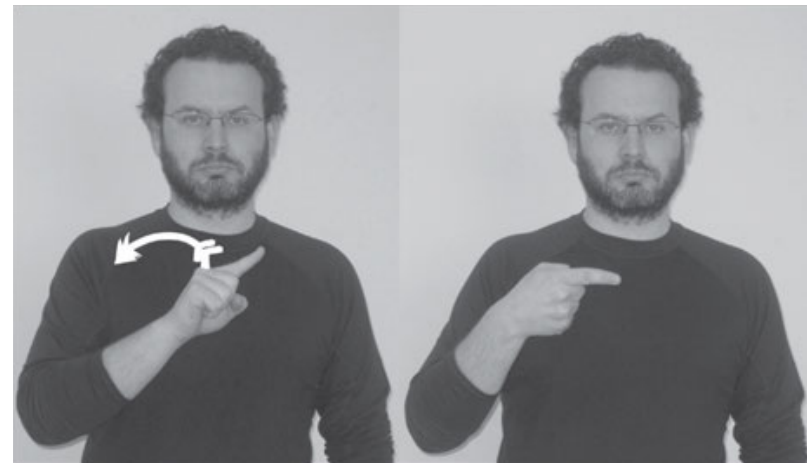

Figure 70. FIRST-FLOOR

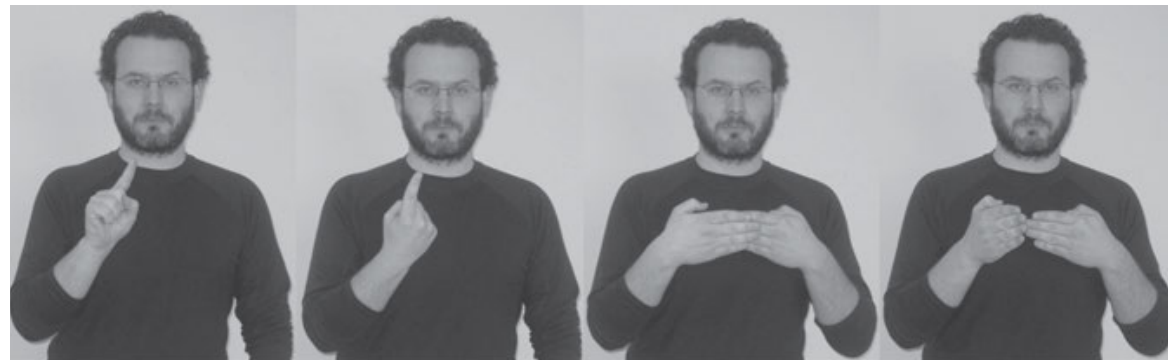

Figure 71. FIRST DOOR

(d) I CAR GARAGE KEEP DESCEND UNTIL [BIM] UNDERGROUND-PARKING_THIRD [HORIZ] CL:CAR-KEEP 'I keep my car on floor -3 at the garage.'

\subsection{Numeral incorporation}

Numeral incorporation is a process by which two signs which exist independently in the language (a numeral quantifier and a quantified unit) are fused, giving rise to a single sign whose meaning includes the meanings of both components. The sign for the quantified unit maintains all of its parameters with the exception of the handshape, which is modified when adding the 
information of numerical quantity. In LSE, numerals can be incorporated into a large number of signs, and they include numbers one through ten, which is an interesting fact as in other sign languages incorporation includes only numbers one through five.

In LSE, as in other sign languages, the use of numeral incorporation appears to correlate with the articulatory characteristics of the signs, specifically with the occurrence of a 'one'-handshape (with the index finger extended and all the other fingers closed in a fist) in citation form. Furthermore, we have verified that in LSE, most signs that allow for numeral incorporation relate to temporal concepts; this is a recurring tendency in all sign languages (Sagara \& Zeshan 2013). In particular, in LSE, the temporal signs that allow for numeral incorporation are the following: SECOND, HOUR, DAY (in one of its forms), WEEK, MONTH, and YEAR. Numeral incorporation is also used with other signs, such as those used to express educational levels (ELEMENTARY and SECONDARY), and with classifiers such as person (by extending as many fingers as the number of individuals referred to).

(e) I PAST THREE\#YEAR\#AGO I JOB FIRED // NOW LOOK LET'S-SEE FUTURE ONE\#MONTH OR TWO\#MONTH FIND JOB LET'S-SEE

'I was fired three years ago. Now I'm looking for a job. I hope I'll find something in one or two months' time.'

We have observed numeral incorporation of ordinals in very few signs in LSE. For instance the sign 'FLOOR', which is normally signed with the index finger of the dominant hand extended and facing left (in right-handed individuals). The wrist is twisted at the same time as the hand is moved to the right. If we wish to indicate the floor number, the number of fingers is increased in correlation with the number of floors (without twisting the wrist). As for signs that refer to temporality, the only one that allows for ordinal numeral incorporation is 'WEEK'. This sign is produced with the thumb of the dominant hand extended and the other fingers closed in a fist, and a straight movement parallel to the chest from left to right (if the signer is right-handed). Characteristic of this incorporation is that it happens in the passive hand, which is used as an iconic referent. 


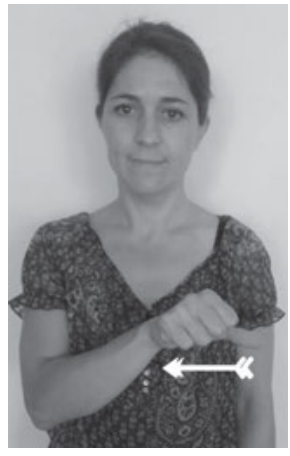

Figure 72. WEEK

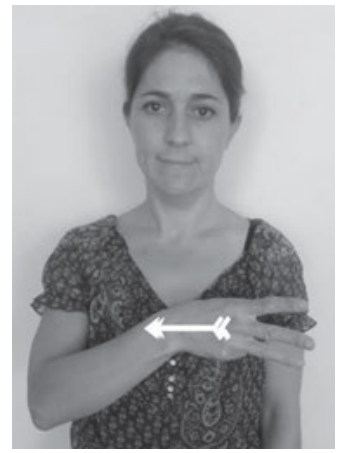

Figure 73. THREE_WEEKS

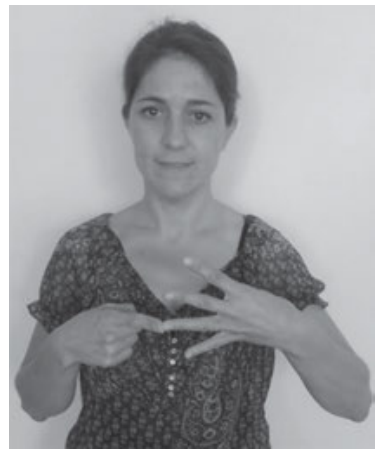

Figure 74. THIRD_WEEK

\subsection{Numerals: Summary and discussion}

Our analysis of variation in the numeral system of LSE confirms the hypothesis that lexical change is related to the social characteristics of the deaf community. In spite of the fact that LSE has a rather stable numeral system, we have been able to document variants due to age, gender, schooling, and communicative situation. Interestingly, the status of regional variation is itself perceived in two different ways, in terms of the region or in terms of schooling. Some of our consultants associate geographical variants with different cities or autonomous communities, but not with the different Schools for the Deaf. This occurs mainly in the case of the younger consultants.

From the articulatory point of view, we have found the following possibilities of variation:

1. The change in the orientation of the palm of the hand: if the interlocutors are close, the numerals are signed with the palm facing the signer, but if they are situated at a certain distance, they are signed with the palm facing outwards, as this improves visualisation. Also, in some of the signs analysed in this study, the difference in orientation occurs systematically but not for contextual reasons. Rather, the difference occurs in some geographical regions. In other cases, as with ordinals, the changes in orientation of numeral signs are due to the orientation of the referents that are being mentioned ('DOOR', 'FLOOR').

2. The simplification of the articulation of the sign, i.e. one-handed articulation of signs that in their standard variant are bi-manual, and which is motivated both by the context of signing (for example, if one of the signer's hands is occupied and in informal discourse), and by the age of 
the signers (this weak hand drop is more characteristic of young signers than of older signers).

3. In terms of lexical variation, in addition to the standard numeral system, which is more common in formal registers, there are lexical variants, specifically in the expression of the tens, the hundreds and the thousands. The most conspicuous lexical variants are those that occur in the Galician numeral subsystem of the multiples of ten. This vigesimal sub-system is used principally by adult deaf individuals who attended the School for the Deaf at Santiago de Compostela. ${ }^{18}$

4. As far as the discourse level is concerned, we have documented some variants depending on the signs co-occurring with the numeral, or on the emphasis that the signer wishes to express with the information transmitted. There are variants which are preferred in colloquial contexts and others which are preferred in formal contexts, the latter generally because they are articulated in a clearer and more visible way.

\section{Conclusions}

In this research, we have attempted a description of colours and numerals, listing both articulatory variants and variation in meaning, making use of lexical inventories and studying the context of usage. However, for an evaluation to be extended to LSE, a larger quantity of data and a larger number of consultants (and more variety in both) would be necessary.

The diatopic variations in the signs analysed do not usually make them incomprehensible to the signers in other geographical areas. This is so in the case of colours and also in the case of numerals, although some of the diatopic variants described for the tens are found to be incomprehensible or unknown to the sign language users in other areas, or even for younger signers. Of particular interest has been the existence of a typologically rare vigesimal sub-system in the Galician variety of LSE.

No specific place of articulation has been found that would correlate with colour terms: the place of articulation of a colour term can be the face, the mouth, the neck or the upper part of the chest and the hands. However, the diachronic variants found for some colours - as in the case BLACK suggests that the linguistic changes in signs for these colours coincide with the general tendency towards phonological reduction to a limited range of articulatory locations on the hands and face, instead of the arms and the shoulders. 
With respect to the iconicity and semantic motivation of the signs, it is clear that the relationship between the signifier and the signified in some of the colour terms depends on influence from the spoken language. This is evident in the derivation from fingerspelling of some signs ('green', 'violet', and 'blue') as well as in those signs that correspond to an object that exhibits this colour ('orange' and 'chestnut brown'), and where this coincides with the denomination in spoken Spanish. When it comes to using colours to express symbolic values, only 'black' and 'white', or 'grey', are used in order to express emotions or feelings in LSE.

The lack of a corpus of LSE, and the scarcity of descriptive and sociolinguistic studies on lexical variation in the Iberian Peninsula and specifically in Spain have been drawbacks that have not allowed us to establish more definite conclusions in some parts of this study. More extensive research remains to be carried out when adequate tools become available.

\section{Notes}

1. Members of the GRILES (Grupo de investigación de lengua española \& lenguas signadas) Research Group at the University of Vigo, Spain. We want to give our heartfelt thanks to Lucía González Carballás and Herminda Otero Doval for their invaluable help in preparing some essential data we used in this article. They reviewed a great number of LSE dictionaries and handbooks, conducted most of the interviews with our LSE consultants, produced the photographs and participated in the recordings of the signs used as examples in this article.

2. For this research we are grateful for the support of the Xunta de Galicia (Galician Automous Government-Cod. 10PXIB302020PR) and the Ministerio de Educación, Cultura y Deporte (Ministry of Education, Culture and Sports - Cod. FFI2010-20972). We also wish to acknowledge our gratitude to our consultants (not only from Galicia but also from other areas of the Kingdom of Spain, such as Madrid and the Canary Islands) and to Marta Dahlgren, responsible for the thorough linguistic and stylistic revision of the chapter presented here.

3. We want to thank all our consultants: Manuel, Claudia, Mónica and Estefanía for their help in answering the questionnaires used for this project, and Rayco, María, Juan Ramón, Alba, and Ruth for their detailed examples.

4. The letter $\mathrm{S}$ is shown in square brackets to indicate where the original quotes were in Spanish, and were translated into English by the authors. 
5. Lexical variation in numerals and colours that are represented are the lexical items colores, blanco, negro, rojo, azul, verde, (colours, white, black, red, blue, green) and the numbers siete, cien, mil (seven, hundred, thousand).

6. The Diccionario normativo de la lengua de signos española (2011) is the printed version of an earlier format on DVD, 2008, which has been revised and improved. It is a bilingual dictionary (LSE-Spanish) and contains 3,700 signs in the standard variety.

7. For an account of LSE dictionaries, see: Báez Montero, Inmaculada (2007).

8. (112) GOLDEN. The sign for counting money is made, elevating the right hand, and making the sign for 'shine'.

9. (109) DARK. Both hands are joined, and at the same time the eyes are closed.

10. (27) SHINE, GLOW, etc. The hand is lifted with the fingers stretched out, separate, and the hand is shaken several times in order to imitate shine and reflexes.

11. We want to thank Patricia Álvarez Sánchez for editing and processing the photographs used in this chapter.

12. Morado in Spanish describes a colour slightly different in tonality to that indicated by the English terms purple and violet.

13. In other Romance languages the variety of terms to express colour is scarcer than in Spanish.

14. Vídeo diccionario de LSE: Sematos. Retrieved from www.sematos.eu

15. McKee et al. (2008:302-303) refer to another possibility of expression, using the index finger to write the numbers in the air. This expression is used by older signers. We do not have sufficient data to be able to assert whether this possibility exists in LSE.

16. On the site http://www.ilsehelp.com/ there is a resource for LSE interpreters, where videos of the standard numeral system can be found, and also the Galician variant of the tens. Note that the number ' 80 ' on this site is signed by merely making contact with the finger tips, and there is no change in hand orientation. This variant is more regular, as none of the other signs in this subseries has any hand orientation change.

17. Pinedo Peydró (2005), Cecilia Tejedor (2006) and Herrero Blanco (2009)

18. In Báez Montero and Fernández Soneira (2010) the problems brought about by the process of standarisation are discussed, and examples are given of indefinite quantification, by means of an analysis of lexical variants of the concept 'todo (all)'. 


\section{References}

Aitchison, Jean. 2001. Language Change: progress or decay? Cambridge University Press

Amaral, M. A., A. Coutinho and M.R.D. Martins. 1994. Para uma gramatica da língua gestua portuguesa. Lisboa: Caminho

Báez Montero, I.C. 2007. Los diccionarios de lenguas de señas españolas: Historia. In M. Campos Souto, E. Conde Noguerol, J.I. Pérez Pascual \& J.-Á. Porto Dapena (eds.) Reflexiones sobre el diccionario, Anexos de Revista de Lexicografia. A Coruña: Universidad de A Coruña, pp. 119-138.

Báez Montero, I.C. \& A. Fernández Soneira. 2010. Problemas de estandarización en la lengua de signos española: la variación entre las comunidades lingüísticas. In J.L. Bueno Alonso, D. González Álvarez, Ú. Kirsten Torrado, A.E. Martínez Ínsua, J. Pérez-Guerra, E. Rama Martínez \& R. Rodríguez Vázquez (eds.) Analizar datos > Describir variación. Servizo de Publicacións da Universidade de Vigo, pp. 1080-1090.

Boyes Braem, Penny \& Rachel Sutton-Spence (eds.). 2001. The hands are the head of the mouth: the mouth as articulator in sign languages. Washington: Gallaudet University Press.

Berlin, Brent \& Paul Kay. 1969. Basic Color Terms: their Universality and Evolution. Berkeley and Los Angeles: University of California Press.

Cecilia Tejedor, A. 2006. Mil palabras con las manos: expresiones naturales, idioma de signos y un vocabulario básico de la lengua de signos española. Madrid: Ciencias de la Educación Preescolar y Especial, D.L.

Corazza, Serena \& Elena Pizzuto. 1996. Noun Morphology in Italian Sign Language (LIS). In H. Van der Hulst \& A. Mills (eds.) Sign Linguistics: Phonetics, phonology and morpho-syntax, Lingua 98, 1-3, pp. 169-196.

Chapa Baixauli, C. 2000. La variación en la LSE. In A. Minguet Soto (coord.) Signolingüistica. Introducción a la lingüistica de la L.S.E. Valencia: Fundación Fesord, pp. 299-310

Chapa Baixauli, C. 2001. La variación del registro en lengua de signos española. Valencia: Fundación Fesord.

CNSE. 1999. Diccionario de la lengua de signos española: neologismos. Madrid: Confederación Nacional de Sordos de España.

CNSE. 2008. Diccionario normativo de la lengua de signos española (DILSE III). Madrid: CNSE. Ed. in CD-Rom.

CNSE. 2011. Diccionario normativo de la lengua de signos española (DILSE III). Madrid, CNSE. Printed version.

Everett, Dan L. 2005. Cultural Constraints on Grammar and Cognition in Pirahã. Current Anthropology 46 (4): 621-634. 
Fernández Soneira, A.Ma . 2008. La cantidad a manos llenas. La expresión de la cuantificación en la lengua de signos española. Madrid: Fundación CNSE.

Fernández,V, P. Pulgarín, F. Martín and I. Samadi. 2013. Primer recull toponímic de Catalunya en Llengua de Signes Catalana (LSC). FUNDACIÓ ILLESCAT.

Fernández Villabrille, F. 1851. Diccionario usual de mímica y dactilología. Útil a los maestros de sordo-mudos, a sus padres y a todas las personas que tengan que entrar en comunicación con ellos. Available online: http://bib.cervantesvirtual. com/servlet/SirveObras/04691602177113816303413/index.htm

Fuentes, M. 2000. Los numerales en la lengua de signos catalana. Sintagma 12: 19-35.

Gras Ferrer, V. 2006. La comunidad sorda como comunidad lingüística: panorama sociolingüístico de la/s lengua/s de signos en España. Ph. D. diss., Departament de Lingüística, Universitat de Barcelona.

Herrero Blanco, Á. 2003. Escritura alfabética de la lengua de signos española. Servicio de publicaciones de la Universidad de Alicante.

Herrero Blanco, Á. 2009. Gramática didáctica de la lengua de signos española (LSE). Madrid: SM.

López Morales, H. 2004. Reprint. Sociolingüística. 3d ed. Madrid: Editorial Gredos. Original edition, Madrid: Gredos, 1989.

Marroquín Cabiedas, J.L. 1975. El lenguaje mímico. Madrid: Federación Nacional de Sociedad de Sordomudos de España.

Marroquín Cabiedas, J.L. 1981. Diccionario mímico español. In suplementos del Faro del Silencio.

McKee, David, Rachel McKee \& G. Major. 2008. Sociolinguistic Variation in NZSL Numerals. In R.M. de Quadros (ed.) Sign Languages: Spinning and unraveling the past, present and future. Petrópolis/RJ, Brazil: Editora Arara Azul, pp. 296-313

Morales López, E. 2008. La lengua de signos como vehículo de comunicación y de capital simbólico. Avaliable online: http://ruc.udc.es/dspace/ bitstream/2183/645/4/LScomocapitalsimb\%C3\%B3lico2008.pdf

Parkhurst, Stephen \& Diane Parkhurst. 2000. La Variación en las Lenguas de Signos: Un estudio de causas y una metodología analítica. In Apuntes de linguistica de la lengua de signos española, VVAA, 219-246. Madrid: CNSE.

Pinedo Peydró, F-J. 2005. Reprint. Diccionario de la lengua de signos española. Madrid: CNSE, D.L. Original edition, Madrid: CNSE, D.L., 2000.

Rodríguez González, M. 1992. Lenguaje de signos. Madrid: Confederación Nacional de Sordos de España and Fundación ONCE.

Sagara, Keiko \& Ulrike Zeshan. 2013. Typology of cardinal numerals and numeral incorporation in sign languages. Poster presented at the $11^{\text {th }}$ Theoretical Issues in Sign Language Research (TISLR) conference at the Deafness, Cognition and Language Centre at University College London, 10-13 July 
Sematos. 2009. Vídeo diccionario de LSE. Available at: http://www.sematos.eu/lse. html [Accessed on 1 July 2015.]

Stamp, Rose, Schembri Adam, Jordan Fenlon and Ramas Rentelis. 2010. Sociolinguistic variation and change of British Sign Language number signs. Poster presented at the sessions of TISLR10: Theoretical Issues in Sign Language Research Conference. Available online: http://www.slls.eu/output/ posters/TISLR10_Stamp.pdf?PHPSESSID=bc57261a3c2d61906a11fa29ee3 $46 \mathrm{e} 01$

Valli, Clayton. \& Ceil Lucas (2000, $3^{\mathrm{a}}$ ed.). 1992. Linguistics of American Sign Language. An Introduction.

Wierzbicka, Anna. 1996. Semantics. Primes and Universals. 
